\title{
Experimental Investigation of Photostrictive Materials for MEMS Application
}

\author{
Mosfequr Rahman', Mahbub Ahmed², Masud Nawaz', Gustavo Molina1, Abdur Rahman³ \\ ${ }^{1}$ Georgia Southern University, Statesboro, GA, USA \\ ${ }^{2}$ Southern Arkansas University, Magnolia, AR, USA \\ ${ }^{3}$ Edinboro University, Edinboro, PA, USA \\ Email:mrahman@georgiasouthern.edu
}

How to cite this paper: Rahman, M., Ahmed, M., Nawaz, M., Molina, G. and Rahman, A. (2017) Experimental Investigation of Photostrictive Materials for MEMS Application. Open Access Library Journal, 4: e3856.

https://doi.org/10.4236/oalib.1103856

Received: July 31, 2017

Accepted: November 27, 2017

Published: November 30, 2017

Copyright $\odot 2017$ by authors and Open Access Library Inc.

This work is licensed under the Creative Commons Attribution International License (CC BY 4.0).

http://creativecommons.org/licenses/by/4.0/

\begin{abstract}
Micro-Electro-Mechanical-Systems (MEMS) is an emerging technology that integrates micromachined mechanical structures with integrated circuits (IC). During the last two decades, it has grown vastly as a prominent research area among scientists and engineers. Usually the main components of MEMS are sensors, actuators, and structures with all in microscale. A photostrictive material has high potential to be used in a MEMS application to develop an advanced optical actuator. A strain is induced when a photostrictive material is illuminated by high intensity light, which is known as photostriction. This phenomenon can be generally described as the combined effect of the photovoltaic effect and the converge-piezoelectric effect. When an incident light strikes a photostrictive material, a photovoltage is produced and this photovoltage develops strain in the material. Lanthanum modified lead zirconate titanate $(\mathrm{Pb}, \mathrm{La})(\mathrm{Zr}, \mathrm{Ti}) \mathrm{O}_{3}$ ceramic doped with $\mathrm{WO}_{3}$, called PLZT, is one of the photostrictive ceramics which has an advantageous use as a wireless remote control over traditional actuators. Traditional actuators require wire connections to transmit the control signal; these wires yield noise via external electromagnetic fields. Whereas, PLZT actuators can transmit the control signal without wires which can eliminate possible noise due to the external electromagnetic field. In this current research, the photostrictive effect of a thin PLZT film on a silicon wafer is investigated experimentally. The transverse deflection of the PLZT optical actuator cantilever beam has been measured for stationary continuous light as well as for pulses of light using an optical chopper at various light intensities and focused locations. Results indicate that transverse deflection increases with the increase of light intensity. Also, the maximum transverse deflection at the free end of the cantilever beam for stationary light has been found to be three times larger than that for the pulses of light.
\end{abstract}




\section{Subject Areas}

Mechanical Engineering

\section{Keywords}

MEMS, Photostriction, PLZT, Actuators

\section{Introduction}

Photostriction is a phenomenon in which strain is induced in photostrictive materials by incident light. In principle, this effect arises from a superposition of the photovoltaic effect, i.e., the generation of large voltage from the irradiation of light, and the converse piezoelectric effect, i.e., expansion or contraction under the voltage applied. A "bulk photovoltaic effect" is noticeable in some ferroelectric (or non-centrosymmetric) materials, such as ferroelectric single crystals or polarized ferroelectric ceramics. Along with this photovoltage, the converse piezoelectric effect induces mechanical strain [1]. The combinations of these two effects make these ferroelectric materials candidates for wireless actuator applications, that is, actuators excited by incident light. Photostrictive ceramics are one promising material for micro-fabrication technologies, which have photovoltaic, piezoelectric, and pyroelectric properties. Photostrictive materials offer the potential for development of advanced actuators with many advantages over conventional electro-mechanical actuators, such as non-contact actuation, remote control, and immunity from electric/magnetic disturbances [2]. Many types of micro-fabrication technologies, such as device design, lithography, film formation, and structure and system integration, have been developed [3]. Traditional actuators, like shape memory alloy and piezoelectric materials, have drawbacks for hard-wire connections such as control signal contamination due to external electro-magnetic disturbances. Photostrictive material appears to have potential for less friction and less weight for use in micro-electro mechanical systems (MEMS) due to its ability to be used wirelessly or by remote control. Piezoelectric ceramics have been used commercially as actuators in various fields; it requires hard wiring to supply voltage for actuation. On the other hand, photostrictive actuators can directly convert photonic energy to mechanical motion; they need neither electric lead wires nor electric circuits. A photostrictive type of actuator uses pulses of light instead of electric voltages for actuation. One material that possesses a significant photostrictive behavior under illumination by high-energy light is lanthanum-modified lead zirconate titanate $(\mathrm{Pb}, \mathrm{La})(\mathrm{Zr}, \mathrm{Ti}) \mathrm{O}_{3}$ ceramic doped with $\mathrm{WO}_{3}$, called PLZT. In PLZT ceramics, UV and visible light have been found to excite free electrons within the crystalline structure that have greater than band-gap voltages; this is characteristic of a photosensitive material [4]. Also, like a typical ferroelectric material, PLZT can be poled to a remnant saturation polarization state, and the polarization can be switched by the application of an electric field. Due to these photosensitive and 
ferroelectric responses, PLZT ceramics are often called photo-ferroelectric (PFE) materials.

Many researchers have investigated the characteristics of photostrictive materials and its possible applications for MEMS devices [3] [5] [6] [7]. In this current research, a PLZT optical actuator on a silicon wafer as a cantilever beam is experimentally investigated to understand its response on continuous illumination of light and pulses of light.

\subsection{Motivation of the Research}

Micro-Electro-Mechanical Systems or MEMS technology can be defined as miniaturized mechanical and electro-mechanical elements that are made using micro fabrication techniques. MEMS functional elements are miniaturized structures, sensors, actuators, and microelectronics; the most important elements are the micro-sensors and micro-actuators. Over the last several decades, MEMS researchers have invented large numbers of micro-sensors with many sensing modalities, including temperature, pressure, inertial forces, chemical species, magnetic fields, optics, etc. Most recently, MEMS researchers have developed optical switches and mirrors to redirect or modulate light beams [8]. The present research will experimentally investigate the feasibility of using photostrictive materials for switching applications in MEMS devices. Switching applications in MEMS are used to transfer data and control signals. A traditional transducer needs electrical wire connections, which may contaminate the control signal by external electro-magnetic field interference. Photostrictive materials, on the other hand, do not need an electrical wire to supply voltage for actuation; they require only external light to actuate and may be used for remote sensing.

\subsection{Research Hypotheses}

Transverse deflection of the PLZT optical actuator depends on the light intensity. The deflection of the PLZT optical actuator will vary for the continuous and pulses of lights. Fast response and significant deflection of the PLZT optical actuator under the illumination of light could be used in MEMS applications as a wireless control.

\subsection{Research Objectives}

Photostrictive actuators have the superiority of remote sensing capabilities and freedom from external electric/magnetic disturbances, unlike conventional actuators. Based on this inspiration from current research, a PLZT thin film placed on the top of a silicon wafer is used to support a systematic characterization of photostrictive properties to develop an actuator. The main goal of the research is to investigate the potential of the PLZT material as a wireless actuator to convert photonic energy to mechanical energy.

The objectives of the present research follow.

1) Investigate the photostrictive effect of a continuous high intensity near-ultraviolet 
(UV) light on a PLZT optical actuator cantilever beam, which includes:

- measuring transverse deflection of the photostrictive cantilever beam for UV light focused at three different locations on the beam;

- for each focused location on the cantilever beam, measuring the transverse deflection along the beam at three different light intensities: $250 \mathrm{~mW} / \mathrm{cm}^{2}, 200$ $\mathrm{mW} / \mathrm{cm}^{2}$ and $100 \mathrm{~mW} / \mathrm{cm}^{2}$; and

- observing the time response of the cantilever beam deflection at the free end of the cantilever beam at three different light intensities and focused locations.

2) Investigate the photostrictive effect of the pulses of high intensity UV light on a PLZT optical actuator cantilever beam using an optical chopper, which includes:

- measuring transverse deflection of the photostrictive actuator at three different light intensities: $250 \mathrm{~mW} / \mathrm{cm}^{2}, 200 \mathrm{~mW} / \mathrm{cm}^{2}$ and $100 \mathrm{~mW} / \mathrm{cm}^{2}$; and

- observing the time response of the cantilever beam at the free end of the beam at three different light intensities.

3) Compare the transverse deflections along the optical actuator cantilever beam between continuous and pulses of light conditions at three light intensities.

\subsection{Background of Photostrictive Actuators}

\subsubsection{Characteristics of the PLZT Ceramics}

PLZT compositions are represented as $\mathrm{Pb}_{1-\mathrm{x}} \mathrm{La}_{\mathrm{x}}\left(\mathrm{Zr}_{\mathrm{y}} \mathrm{Ti}_{\mathrm{z}}\right)_{1-\mathrm{x} / 4} \mathrm{O}_{3}$ or $\mathrm{PLZT}(\mathrm{X} / \mathrm{Y} / \mathrm{Z})$, where $X=100 x, Y=100 y$ and $Z=100 z$. Ferroelectric materials have a wide range of properties depending on the composition [3]. The photovoltaic effect was first discovered in $\mathrm{BaTiO}_{3}$ material [9]. P.S. Brody first proposed photostrictive materials as an opto-mechanical actuator, which can be used for MEMS devices to convert optical energy to mechanical energy [10] [11]. When ultraviolet (UV) light falls on the materials, it absorbs photons. Absorbed photons energize electrons and holes to move in a non-random manner; as a result, charges started to flow in an external short circuit of PLZT material. Light illuminates from the top and along the thickness of the material in the $\mathrm{H}$ direction. The photocurrent of PLZT ceramics varies proportionally with light intensity. Photocurrent increases as the thickness of PLZT film decreases, up to a certain limit [12]. The maximum photocurrent is predicted at $33 \mu \mathrm{m}$ thickness for PLZT (3/52/48) ceramic doped with $0.5 \% \mathrm{WO}_{3}$ [13]. If film thickness becomes ultra-thin, then the film does not have enough electrons to flow and photocurrent drops because of the size effect [12]. Photocurrent of PLZT materials also depends on the wavelength of illuminating light. The maximum photocurrent is observed at $365 \mathrm{~nm}$ wavelength of light, which is out of visible light wavelength range [14]. No significant difference in wavelength dependency has been found between impurity-doped or non-doped samples. However, the valence of impurity has a significant effect on the photovoltaic response. Impurity atoms are classified into three categories: acceptors, donors, and remainder. $\mathrm{K}^{+}, \mathrm{Na}^{+}, \mathrm{Mg}^{2+}, \mathrm{Ba}^{2+}, \mathrm{Al}^{3+} \& \mathrm{Fe}^{3+}$ atoms are in the acceptor group; $\mathrm{Bi}^{3+}, \mathrm{Y}^{3+}, \mathrm{Nb}^{5+}, \mathrm{Ta}^{5+} \& \mathrm{~W}^{6+}$ are in the donor group. Photostriction $\left(\mathrm{x}_{\mathrm{ph}}\right)$ can 
be defined in terms of photovoltaic voltage $\left(\mathrm{E}_{\mathrm{ph}}\right)$ and piezoelectric coefficient $\left(\mathrm{d}_{33}\right)$ as $\mathrm{x}_{\mathrm{ph}}=\mathrm{d}_{33} \mathrm{E}_{\mathrm{ph}}$. Impurities-doping has an effect on the piezoelectric coefficient, which improves photostriction [4]. Steady photovoltage and photocurrent generate in non-centrosymmetric ferroelectric material when illumination light has a wavelength corresponding to the absorption edge of the materials [1]. Generated photovoltage is greater than the band-gap energy for some materials. In certain ferroelectric material, photovoltage is about $1 \mathrm{kV} / \mathrm{cm}$ and current is in the order of $\mathrm{nA}$; with this photovoltage, mechanical strain is produced due to converse piezoelectric effect [4] [13]. Several models have been proposed to describe the photovoltaic effect [13]. Photovoltage depends on both impurities-doping as well as crystal asymmetry.

\subsubsection{Literature Review on the Transverse Deflection of the PLZT Cantilever Beam with the Light Intensity}

Tonokai et al. experimentally investigated PLZT on a $8 \mathrm{~mm} \times 2 \mathrm{~mm} \times 0.05 \mathrm{~mm}$ Ti wafer at $50 \mathrm{~mW} / \mathrm{cm}^{2}, 150 \mathrm{~mW} / \mathrm{cm}^{2}, 300 \mathrm{~mW} / \mathrm{cm}^{2}$ and $450 \mathrm{~mW} / \mathrm{cm}^{2} \mathrm{UV}$ light intensities; deflections were found to be $5 \mu \mathrm{m}, 11 \mu \mathrm{m}, 18 \mu \mathrm{m}$ and $25 \mu \mathrm{m}$ respectively [15]. Liang et al. experimented on a single-layer PLZT at $3 \mathrm{~mW} / \mathrm{cm}^{2}, 6$ $\mathrm{mW} / \mathrm{cm}^{2}, 9 \mathrm{~mW} / \mathrm{cm}^{2}, 12 \mathrm{~mW} / \mathrm{cm}^{2}$, and displacements were reported to be 0.31 $\mu \mathrm{m}, 0.33 \mu \mathrm{m}, 0.42 \mathrm{~m}$ and $0.57 \mu \mathrm{m}$ respectively [16]. Liang et al. developed a bimorph with amplificatory plate to reach deflection 100 times that of a single layer. The bimorph is constructed by reversing the polarization direction of a pair of PLZT unilateral wafers. The upper PLZT wafer develops a positive charge and expands due to UV light irradiation, and the lower PLZT wafer develops a negative charge and contracts at the same time; as a result, the entire bimorph bends downwards. Thakoor et al. reported that two PLZT ceramics wafers bond together to make a bimorph. The size of the bimorph is $20 \mathrm{~mm} \times 5 \mathrm{~mm} \times 0.4 \mathrm{~mm}$. The maximum deflection was observed $200 \mu \mathrm{m}$ at the tip at $80 \mathrm{~mW} / \mathrm{cm}^{2}$ [17]. Fukuda et al. experimented on the two pieces of $21 \mathrm{~mm} \times 5 \mathrm{~mm} \times 0.2 \mathrm{~mm}$ PLZT, glued in the opposite direction of polarization; the maximum deflections were observed to be $61 \mu \mathrm{m}, 58 \mu \mathrm{m}$ and $37 \mu \mathrm{m}$ at $200 \mathrm{~mW} / \mathrm{cm}^{2}, 100 \mathrm{~mW} / \mathrm{cm}^{2}$ and $25 \mathrm{~mW} / \mathrm{cm}^{2}$ light intensity respectively [18].

\subsubsection{Literature Review on the MEMS Applications}

Photostrictive effect of PLZT is useful for MEMS applications because it can serve as a current and voltage source for optical sensors at the same time. However, it requires some improvements: 1) improvement of output current; and 2) improvement of response [19]. Using the electrical properties of PLZT, an optical motor was developed as an electro-mechanical device suitable for miniaturization [3]. The optical motor driving principle was described with stator pads and moving pads. The PLZT electrode is connected with stator pads. When light falls on a PLZT electrode, high voltage generates between the stator and moving pad; then the moving pad starts to move towards the stator side. The proposed optical motor rotor disk has four pads, and each stator disk has three pads. The rotor disk was 
fixed or aligned with the motor axis, which is on the bearing. When light falls on PLZT ceramics, high voltage generates in the stator, and the rotor is pulled into the stator in a clockwise direction from the top view. The optical motor could be rotated, but its speed would be very slow. Internet traffic has grown enormously with the development of broadband access; a PLZT optical actuator could play a significant role in high-speed data transfer systems [20]. PLZT actuators can be used as high speed optical switches with benefits including low-voltage, low power consumption, low-polarization independence, noise robustness and switching speed of less than a nano second [21] [22]. Furukawa et al. made a $1 \times 8$ PLZT optical switch whose switching speed is less than $2.5 \mathrm{~ns}$ [23]. Satol et al. developed an $8 \times 8$ channel switch comprised of a PLZT deflector, fiber array, and micro-lens and slab waveguide [7]. Switching speed was less than $1 \mu$ s. PLZT bimorphs could also be used as a photo driven relay, consisting of two ceramic plates bonded together in opposite polarization directions and a dummy PLZT plate placed adjacent to the bimorph. Switching could be controlled by alternately irradiating light on the bimorph and dummy plates [5]. A micro-walking machine was developed using photostrictive bimorphs. Two PLZT ceramic legs are fixed on a plastic board; light irradiates on the legs alternately and the micro-walking machine moves like an inchworm at a very low speed of $10 \mu \mathrm{m} / \mathrm{min}$ [24]. An optical gripper was developed using a PLZT bimorph actuator. There are two bimorph actuators and UV light is irradiated by optical fibers on each actuator independently using two mirrors. Displacement of the gripper at the tip was reported to be $100 \mu \mathrm{m}$. The gripper has strong anti-noise characteristics and could be used for micro-surgery [18]. A photocurrent generates due to irradiation of light on the photostrictive actuator; this property has been used as an image comparator. One image is stored as a sequence of spatially varying ferroelectric domains. The second image is projected on the first and generates a photocurrent representing the dot product of stored and projected images [25]. Photostrictive materials also can be used as solar tracking shutter and photo phone [16]. Photo generated deflection could be used to walk on the surface or to run a motor indirectly. This kind of wireless optical control of an advanced mobile vehicle would be used for hazardous, hard to reach locations, as long as it is in the range of sight. Scattering effect of PLZT has been used to construct display devices and optical shutters, optical information storage and processing [17] [26].

\subsection{Basic Photostriction Equations}

When the high-energy illumination with certain wavelength irradiates the photostrictive optical actuator, a current opposite to the polarized direction is induced. This current generates a voltage between the two surface electrodes, called the photovoltaic effect. The induced photovoltaic voltage induces actuation strains due to the converse piezoelectric effect. The induced electric field $E_{N}(t)$ from the photovoltaic effect can be determined from [27]: 


$$
E_{l}(t)=E_{l}\left(t_{j-1}\right)+\left[E_{s}-E_{l}\left(t_{j-1}\right)\right] \frac{\alpha}{a_{s}} I\left(t_{j}\right) \mathrm{e}^{-\frac{\alpha}{a_{s}} I\left(t_{j}\right) \Delta t} \cdot \Delta t-E_{l}\left(t_{j-1}\right) \beta \mathrm{e}^{-\beta \Delta t} \cdot \Delta t
$$

where $E_{s}$ is the saturated photovoltaic field; $a_{s}=L_{a} / b_{a}$ (length/width) is the aspect ratio; $\alpha$ is optical actuator constant and $\beta$ is a constant related to voltage leakage. The light intensity $I(t)$ is a function of time, and $E_{N}\left(t_{j}\right)$ denotes the induced electric field at time $t_{j}$. While $I(t)$ remains constant during the interval $\Delta t$, then the electric field at $t_{j}=t_{j-1}+\Delta t$ is $E_{l}\left(t_{j}\right)$.

The actuator temperature can be defined in a difference equation [27]:

$$
\theta\left(t_{j+1}\right)=\theta\left(t_{j}\right)+\Delta \theta=\theta\left(t_{j}\right)+\frac{\left[I\left(t_{j+1}\right) P-\gamma \theta\left(t_{j}\right)\right] \Delta t}{H+\gamma \Delta t}
$$

where $P$ is the absorbed heat from the light illumination; $H$ is the heat capacity of the actuator; $\gamma$ is the heat transfer rate from the actuator to the structure; $\theta\left(t_{j}\right)$ is the actuator body temperature at $t_{j} I\left(t_{j}\right)$ is an illumination intensity at $t_{j}$ and $\Delta \theta$ is a temperature rise in a time interval $\Delta t$.

The temperature change can trigger the pyroelectric effect from which an additional voltage is generated. The electric field $E_{\theta}(t)$, contributed by pyroelectric effect, can be determined from [27]:

$$
E_{\theta}(t)=\frac{P_{n}}{\varepsilon} \theta(t)
$$

where $P_{n}$ is the pyroelectric constant.

The total induced electric field $E(t)$ including both the photovoltaic effect and the pyroelectric effect is [27]:

$$
E(t)=E_{l}(t)+E_{\theta}(t)
$$

The magnitude of the light induced strains can be written as [18]:

$$
\bar{S}(t)=d_{33}\left[E_{l}(t)+E_{\theta}(t)\right]+\lambda \theta(t) / Y_{a}
$$

where $d_{33}$ is the piezoelectric-strain constant, $\lambda$ is a thermal stress coefficient, and $Y_{a}$ is the Young's modulus of the optical actuator.

The electric potential of the actuator is

$$
E_{Z}(t)=E(t) \times \text { thickness }
$$

The objective of the current research is to investigate the influence of continuous and pulses of light on the transverse deflection of PLZT optical actuator. How the transverse deflection of a cantilever beam depends on the light intensity (both continuous and pulses) will be investigated experimentally. If the intensity of the light and the focused locations of the beam affect the time response will also be investigated in the current research.

\section{Methodology}

Experimentation has been performed mainly using a high intensity light source, a good repeatability displacement measurement sensor, and a photostrictive opti- 
cal actuator. The goal of the experiment was to observe the transverse deflection of a PLZT thin film on a silicon wafer cantilever beam under the illumination of continuous and pulses of high intensity light.

\subsection{Experiment Method}

\subsubsection{Experimental Set-Up Design and Development}

The experimental test set-up was designed to measure the photostriction effect of a photostrictive optical actuator as shown in Figure 1.

The set-up consists of a high pressure short arc xenon lamp with lamp housing, power supply with igniter, hot mirror, band pass filter, optical chopper, photostrictive cantilever type optical actuator, and laser sensor head with controller. Based on the design, an actual experimental set-up was developed as shown in Figure 2.

A sample of PLZT (3/52/48) ceramic was doped with $0.5 \% \mathrm{WO}_{3}$ of $1 \mu \mathrm{m}$ thin film deposited on top of a $550 \mu \mathrm{m}$ silicon wafer as shown in Figure 3. PLZT material was deposited on the silicon wafer at the MEMS Laboratory of Georgia Institute of Technology using the spattering method. PLZT (3/52/48) means $\mathrm{Pb}$ concentration of $97 \%$, La concentration of $3 \%$ with $\mathrm{Zr} / \mathrm{Ti}$ ratio $52 / 48$. (3/52/48) ceramic also can be represented as $\mathrm{Pb} 0.97 \mathrm{La} 0.03$ ( $\mathrm{Zr} 0.52 \mathrm{Ti} 0.48) 0.99 \mathrm{O}_{3}$.

A 150 watt xenon short arc lamp was provided high intensity light for maximum photovoltaic effect on the optical actuator. The arc lamp was placed inside the Science Tech 201 - 100 series lamp housing. A model 500 - 200 series AC power supply and a model 500-IG igniter were used to turn on the short arc lamp. To produce pulses of high intensity light on an optical actuator the Scitech 300CD model an optical chopper was used. A Keyence LK-H087 laser sensor head with

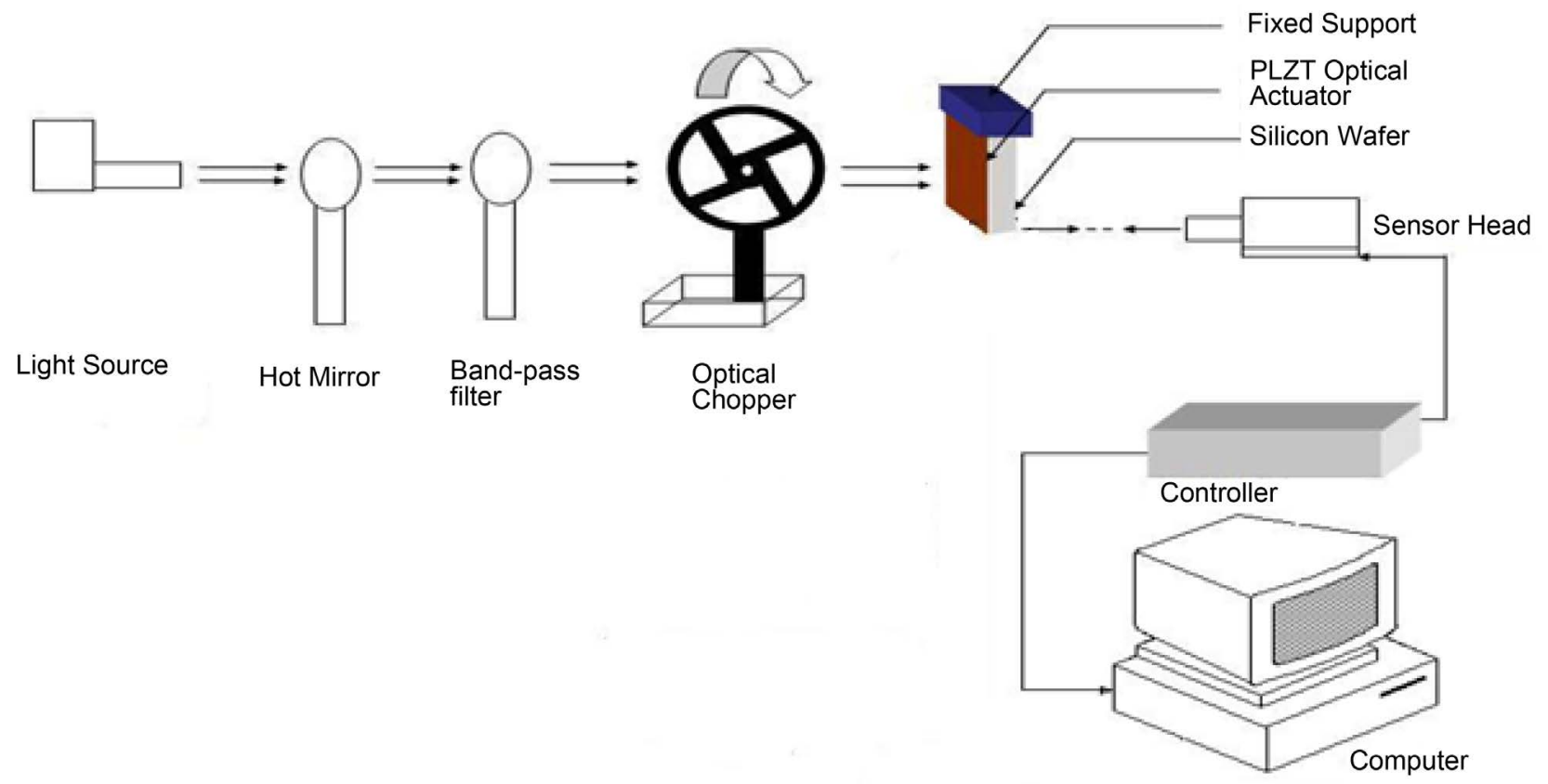

Figure 1. Schematic diagram of the experimental set-up for photostriction effect measurement. 


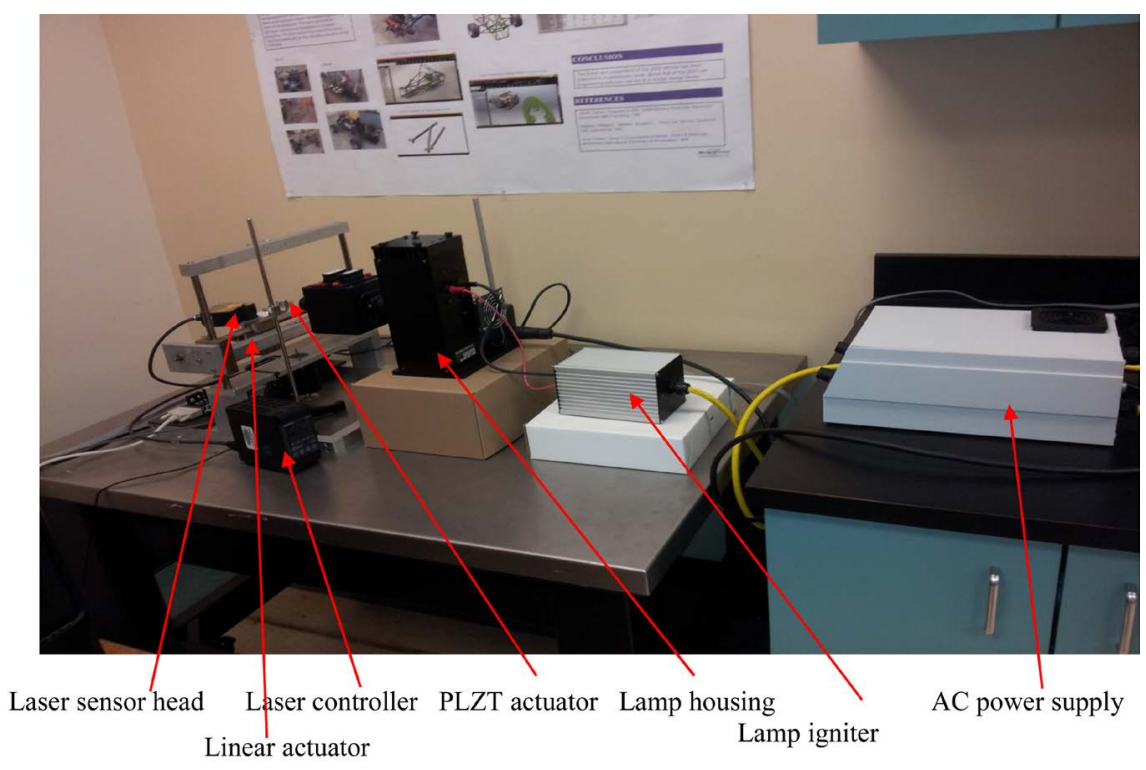

Figure 2. Experiment set-up for transverse deflection measurement of a cantilever beam.

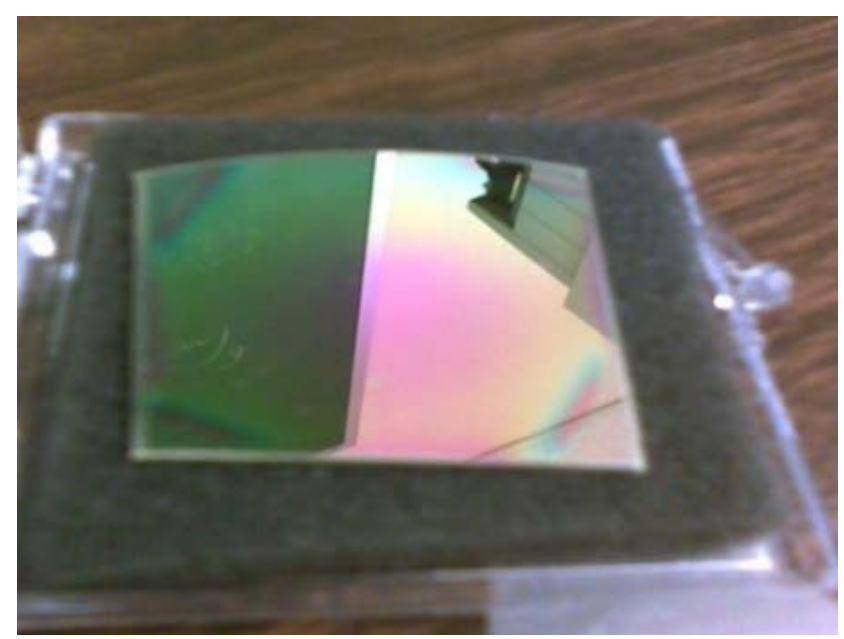

Figure 3. PLZT sample manufactured at the MEMS laboratory.

$0.1 \mu \mathrm{m}$ repeatability was used to measure the transverse deflection of actuator beam. Laser sensor data acquisition was controlled by the Keyence LK-G5001V model laser sensor controller. The beam deflection data was recorded in the computer through the laser sensor controller and data acquisition system. A heat absorbing glass was placed in front of the lamp housing, to filter high wavelength light that was generated by the arc lamp. In addition, a UV band-pass filter was placed behind a heat-absorbing filter, which allowed only $250 \mathrm{~nm}$ to $410 \mathrm{~nm}$ wavelengths of light to pass. This high intensity UV light went through a lamp housing window lens and was used to produce the photostriction effect on the optical actuator. A diamond-cutting blade was used to cut the sample into the desired shape $(18 \mathrm{~mm} \times 8 \mathrm{~mm})$ for the experiment. PLZT thin film on silicon wafer sample was mounted as a cantilever beam on a stand. An LK-H087 laser displacement sensor was mounted on a linear actuator at the other side of the light 
source. The linear actuator can travel a minimum of $0.1 \mathrm{~mm} / \mathrm{step}$ in the horizontal direction, thus allowing the laser displacement sensor head to move along the length of the sample cantilever beam. To irradiate pulses of light on the sample a variable frequency optical chopper was placed between the sample and the lamp housing window lens. Source light beam has a maximum light intensity of $250 \mathrm{~mW} / \mathrm{cm}^{2}$ at its focal point through the lamp housing window lens at $20 \mathrm{~cm}$ distance, which was measured by a UV meter. The UV meter sensor head was 12 $\mathrm{mm}$ in diameter, which measured the intensity on the average of sensor head area.

It was not experimentally possible for the whole cantilever beam to be exposed with equal light intensity. The light intensity starts to decrease as far as from the center of focal point on its perpendicular plane. Experiments were performed by focusing the light on the targeted cantilever beam at three different locations; these are the free end, middle, and fixed end as shown in Figure 4. Using the UV meter the light intensities were measured, at a distance of $20 \mathrm{~cm}, 25 \mathrm{~cm}$, and 35 $\mathrm{cm}$ from the lamp housing window lens, were $250 \mathrm{~mW} / \mathrm{cm}^{2}, 200 \mathrm{~mW} / \mathrm{cm}^{2}$, and $100 \mathrm{~mW} / \mathrm{cm}^{2}$ respectively.

\subsubsection{Experimental Procedure}

In conducting the experiment to produce photostriction effect and measuring the transverse deflection of the actuator, the following steps have been followed:

- A high-pressure short arc xenon lamp was placed properly inside the lamp housing with right polarity of cathode $(-)$ and anode $(+)$. This was used as a UV light source for the experiment.

- A power supply and a lamp igniter were connected to the lamp housing; and the lamp housing was placed on a vibration isolation table.

- A hot mirror lens and a $428 \mathrm{~nm}$ wavelength filter were placed after the lamp inside the housing filter slot. The source light first passed through the hot mirror then through the $428 \mathrm{~nm}$ wavelength filter.

- Output light was focused on the PLZT optical actuator cantilever beam at different distances from the output lens to get various light intensities on the targeted area.

- A frequency variable optical chopper was placed in between the light output lens and the PLZT cantilever beam to produce pulses of light on the targeted area as shown in Figure 5.

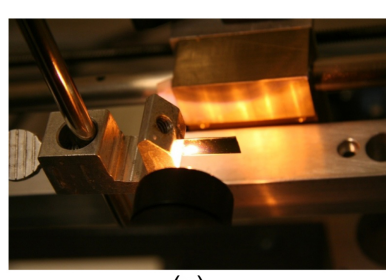

(a)

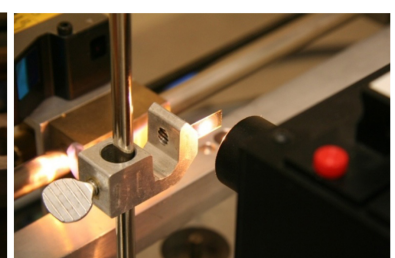

(b)

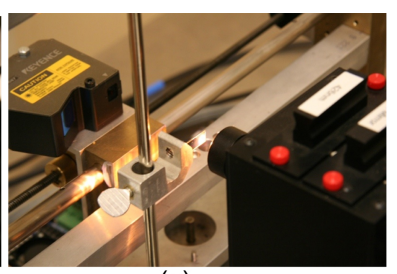

(c)

Figure 4. UV light was focused (a) At the fixed end; (b) At the middle; and (c) At the free end of the cantilever beam. 


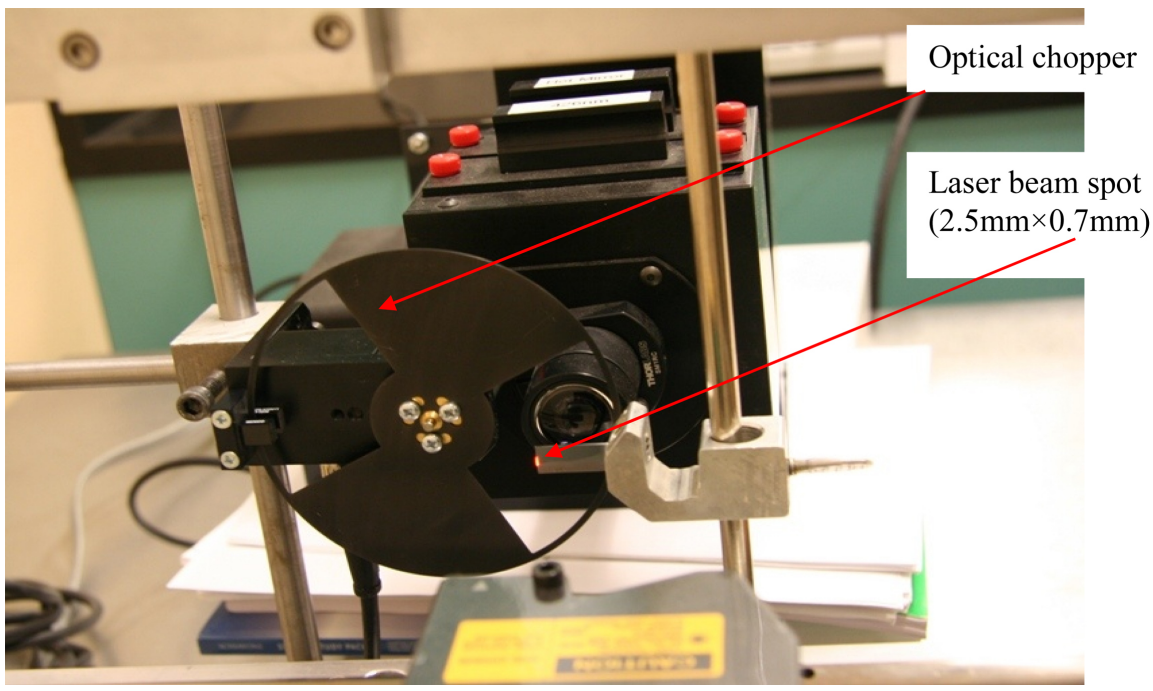

Figure 5. Optical chopper placement in the experiment set up to observe response for the pulses of light.

- The laser displacement sensor head was connected with the controller. The controller was powered by a $24 \mathrm{~V}$ DC adapter. The laser sensor head was placed at the backside of the target that was the opposite side of the light source.

- The controller was connected to the computer by USB port to collect measured data on the personal computer (PC).

- Transverse deflection of the cantilever beam was measured by the laser displacement sensor along the length of the cantilever beam for every $1 \mathrm{~mm}$ distance from the free end. All measured data was recorded on the PC.

- Data was collected from the laser sensor at $0.1 \mathrm{sec}$ intervals. An average of 20 - 30 seconds of collected data was recorded for analysis as shown in Figure 6.

- During the experiment, the photostrictive optical actuator cantilever beam was exposed for 5 minutes to the high intensity UV light then light was turned off and data was collected for 3 minutes.

- The average of three sets of data was plotted for the analysis.

\section{Results}

\subsection{Results of the Cantilever Beam for the Continuous Light}

A photostrictive optical actuator was exposed under the uniform illumination of UV light for a certain period of time. Transverse deflection of the PLZT optical actuator cantilever beam is analyzed at various light intensities and various focused light positions. Comparison of transverse deflection is also presented.

\subsubsection{Dependence of Transverse Deflection on Light Intensity at Specific Light Focused Position}

Transverse deflections of the cantilever beam at $250 \mathrm{~mW} / \mathrm{cm}^{2}, 200 \mathrm{~mW} / \mathrm{cm}^{2}$, and $100 \mathrm{~mW} / \mathrm{cm}^{2}$ light intensities were observed with light focused at different locations on the beam. Data plotted along the length of the cantilever beam are 


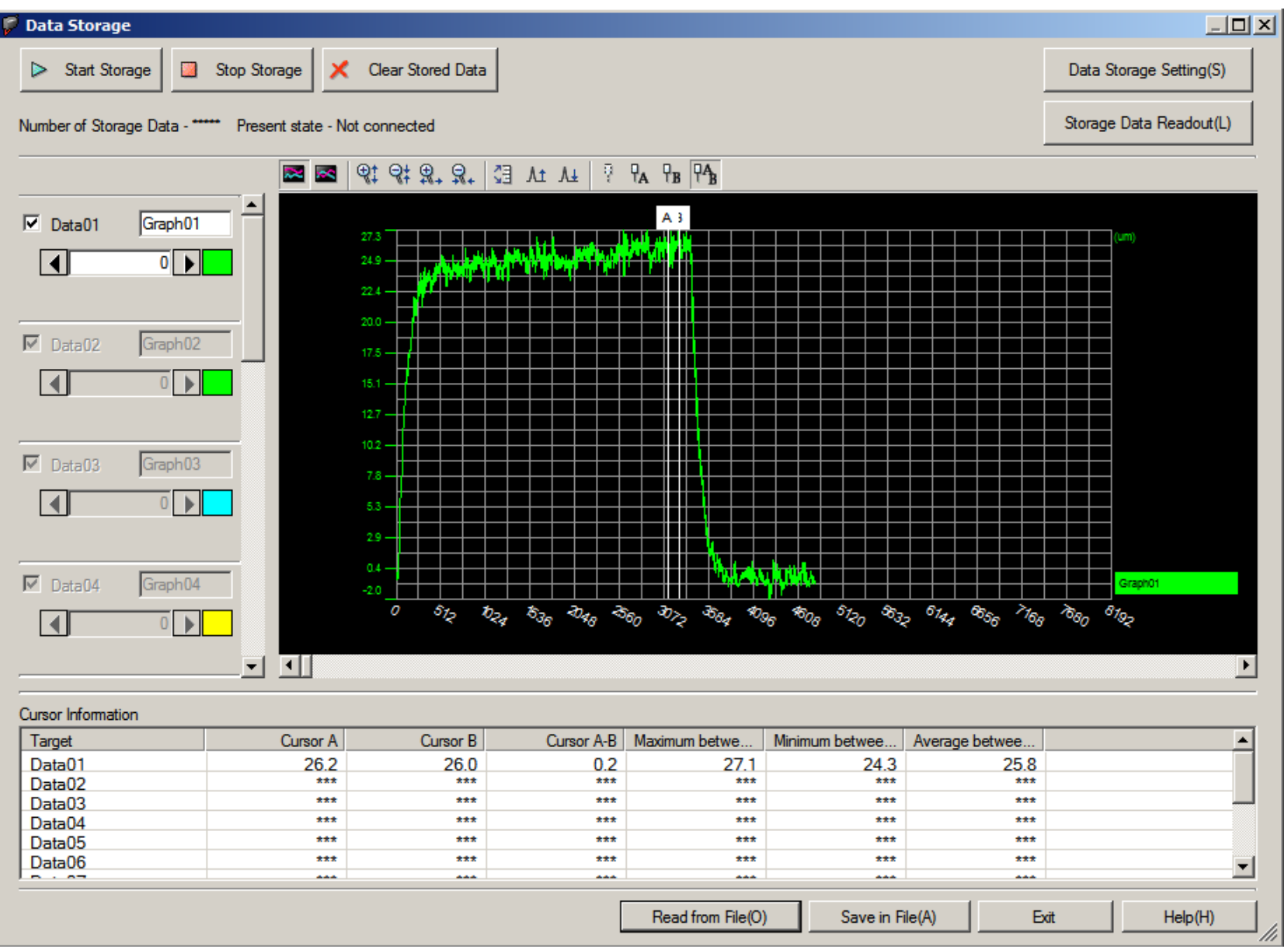

Figure 6. Controller output data collected in every $0.1 \mathrm{sec}$ interval for $480 \mathrm{sec}$.

shown in Figures 7-9 respectively. Deflections were measured every $1 \mathrm{~mm}$ distance along the length of cantilever beam. The negative deflection means the cantilever beam was deflected in the opposite side of the light source. From the figures, it can be seen that the transverse deflection near the fixed end of the beam was very small; it increased with the increase of distance from the fixed end. The maximum transverse deflection was observed at the free end of the beam. In addition, transverse deflection of the beam depends on the light intensity and it increases with the increase of light intensity at each specific focused location of the cantilever beam as shown in Figure 10.

\subsubsection{Dependence of Transverse Deflection on Light Focused Position at Specific Light Intensity}

Transverse deflection of the beam also depends on the locations of light focused on the beam. Deflection was maximized when the light was focused near the fixed end of the beam and it was minimized when the light was focused at the free end. Variation of transverse deflections due to light focused position variations were observed for three specific light intensities as shown in Figures 11-13. Deflections of the beam when the light was focused at the middle and at the free end were almost the same at the $250 \mathrm{~mW} / \mathrm{cm}^{2}$ as shown in Figure 11. At 200 


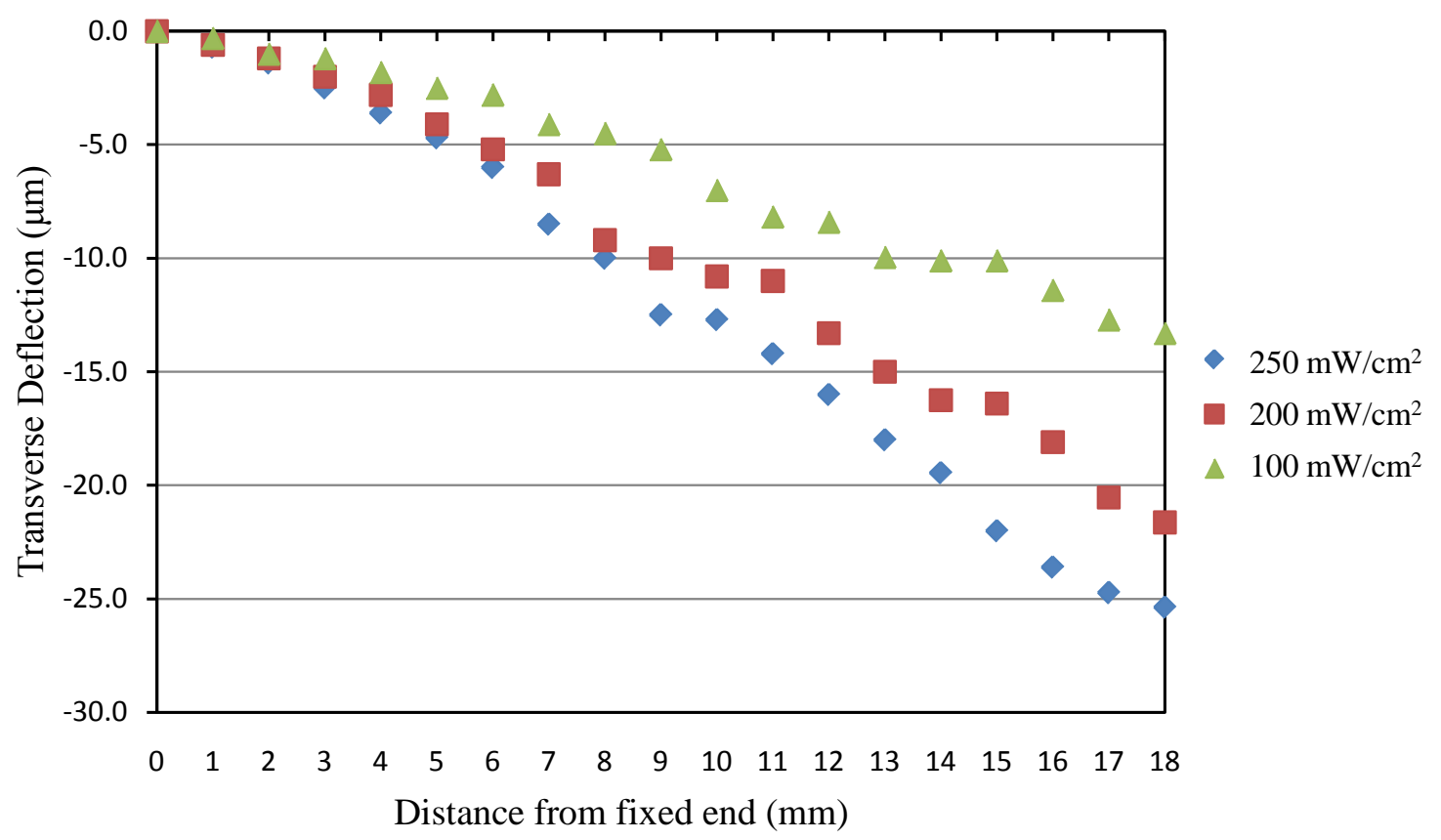

Figure 7. Comparison of transverse deflection for three different light intensities when light was focused at the fixed end of the cantilever beam.

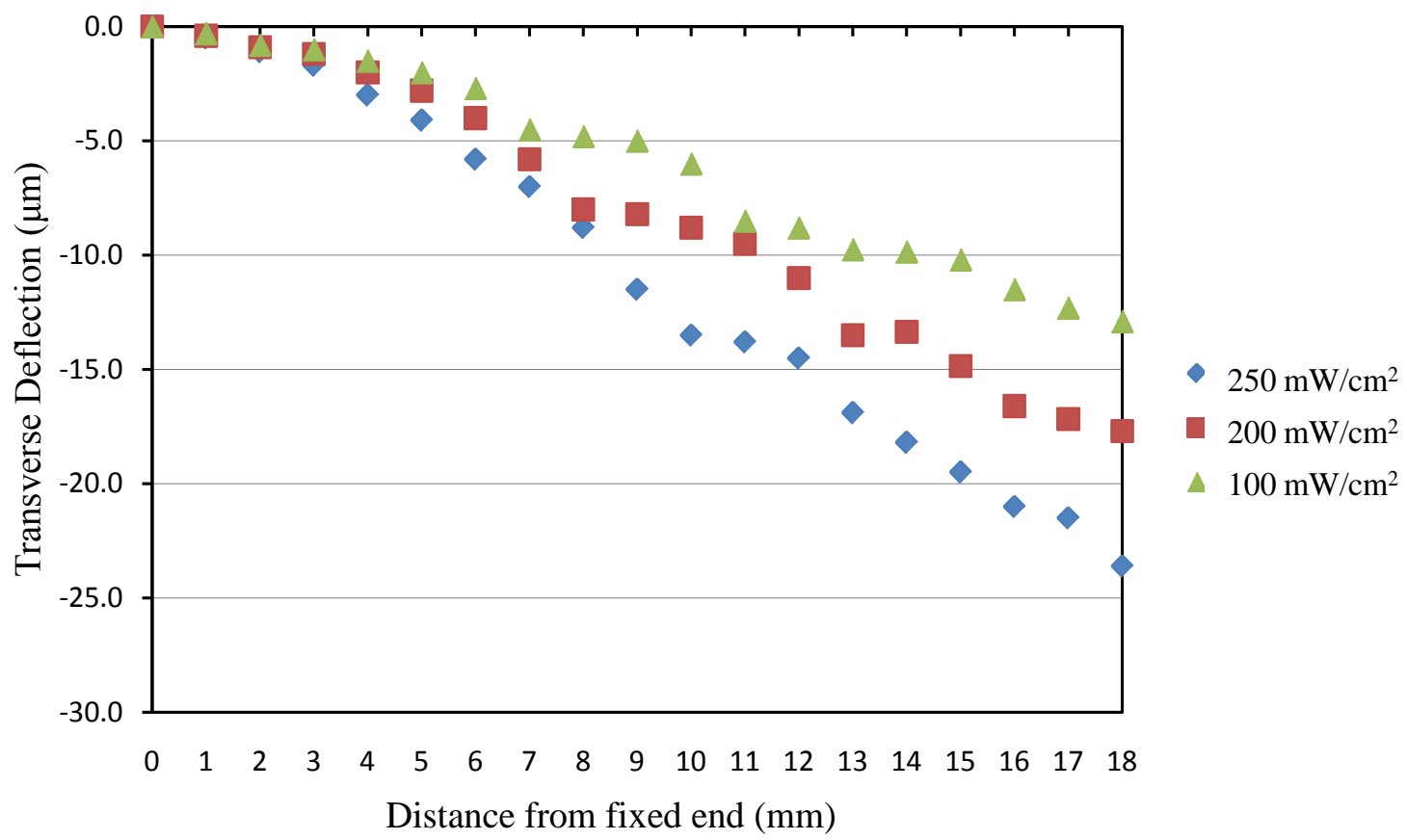

Figure 8. Comparison of transverse deflection for three different light intensities when light was focused at the middle of the cantilever beam.

$\mathrm{mW} / \mathrm{cm}^{2}$, when light was focused at the middle, deflection of the beam was more than the deflection when the light was focused at the free end but less than the deflection when the light was focused at fixed end as shown in Figure 12. When the gap between the light source and the targeted area of the beam increased, 


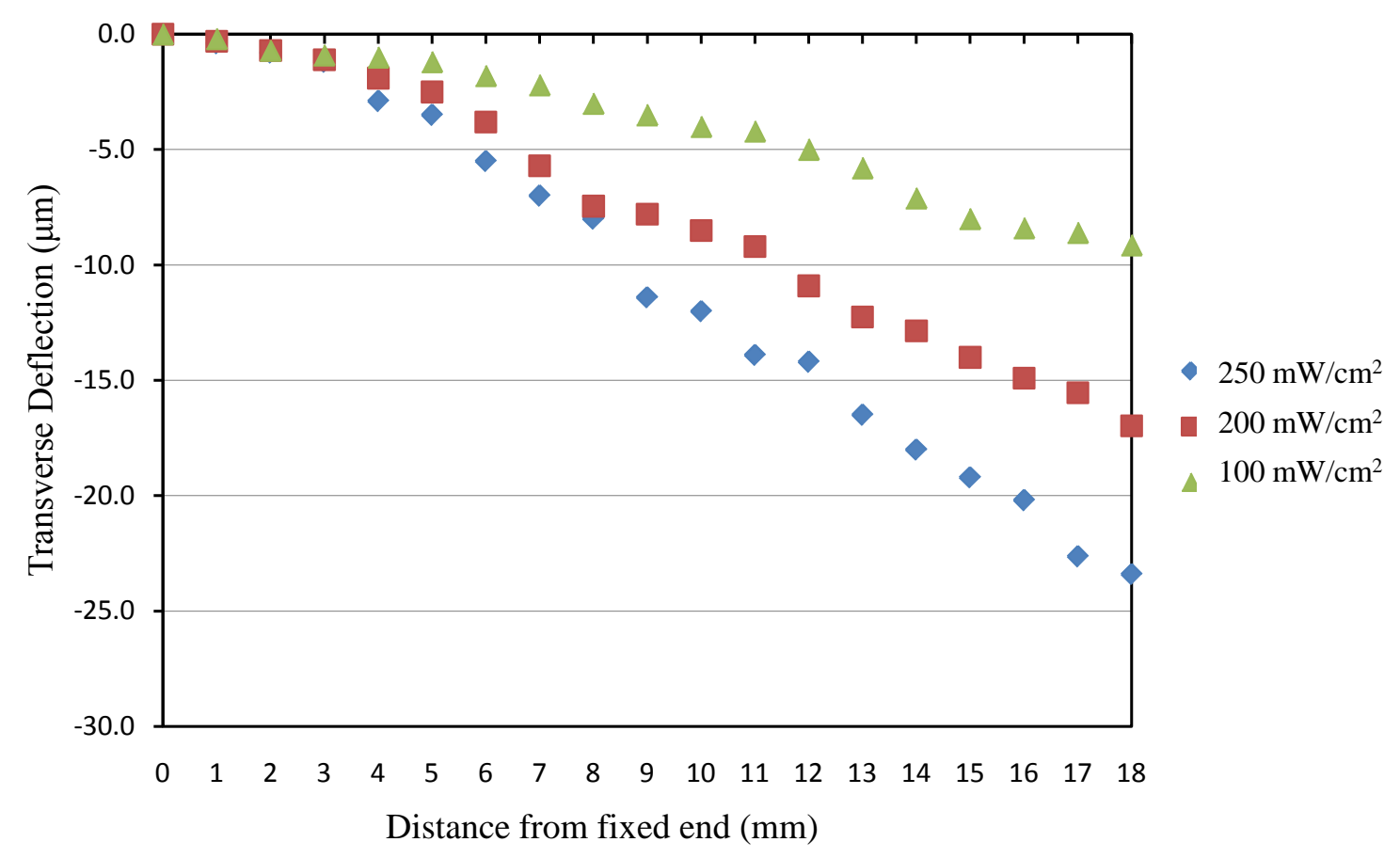

Figure 9. Comparison of transverse deflection for three different light intensities when light was focused at the free end of the cantilever beam.

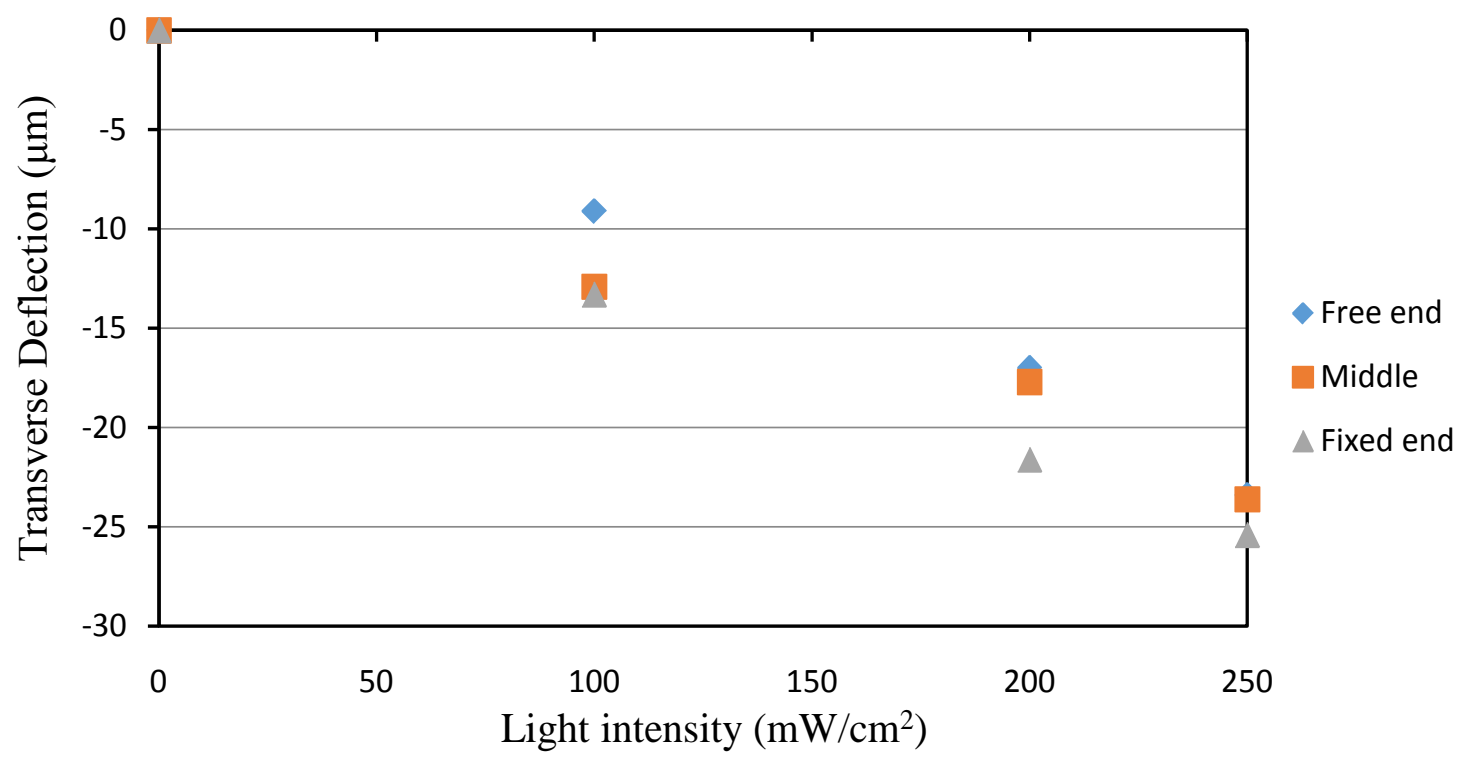

Figure 10. Transverse deflection at the free end of the beam with three different light intensities for three different focused locations on the cantilever beam.

the light beam diffused and allowed the cantilever beam to expose more light to the actuator surface; this happened especially when the light was focused at the middle position compare to the other two positions. At $100 \mathrm{~mW} / \mathrm{cm}^{2}$, the deflections were the same when the focused position of the light was at the middle and at the fixed end of the cantilever beam as shown in Figure 13. More diffused light fell on the beam surface when the light was focused at the middle of the 


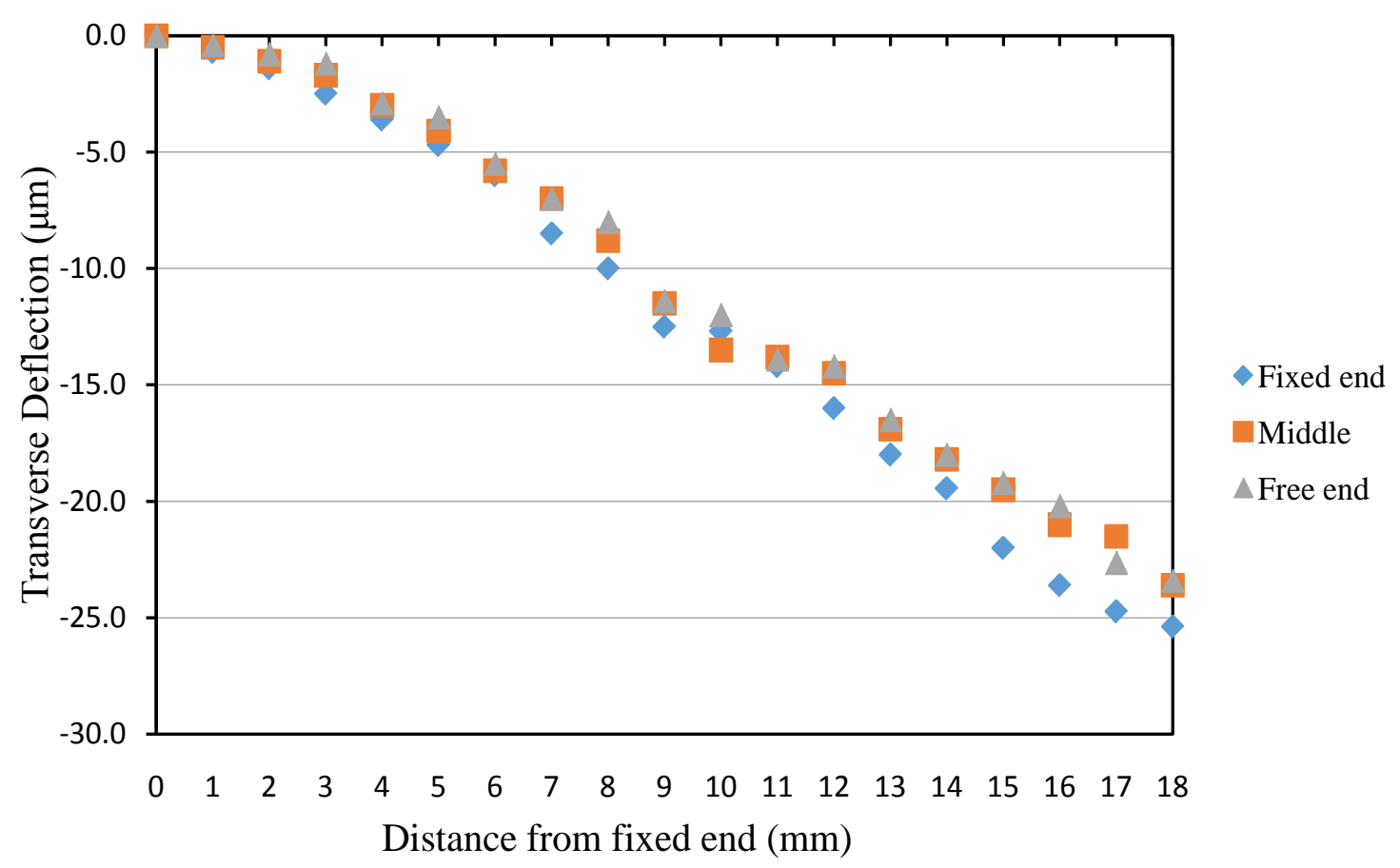

Figure 11. Variation of transverse deflection along the length of the cantilever beam for three different light focus positions on the beam at $250 \mathrm{~mW} / \mathrm{cm}^{2}$.

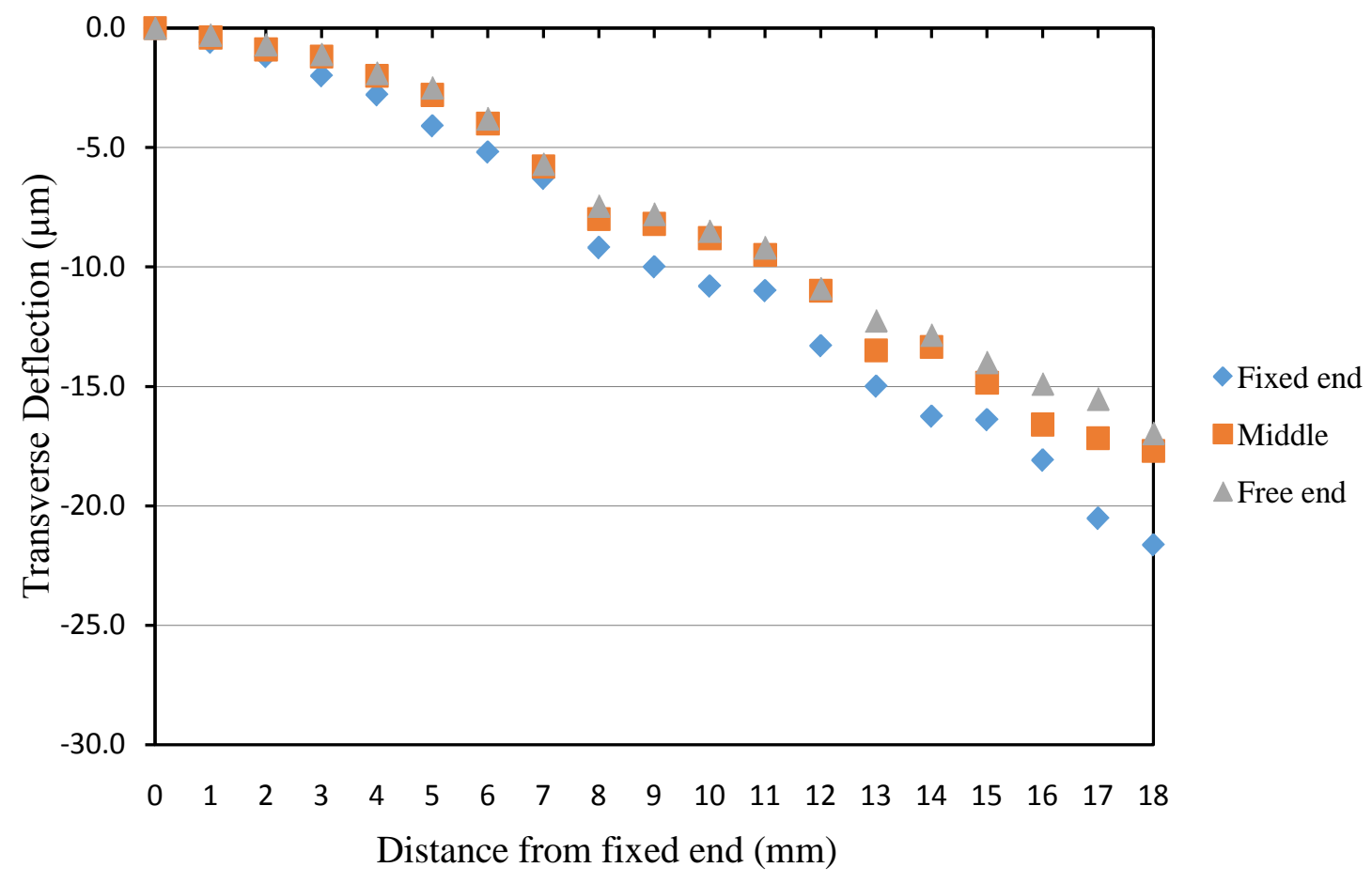

Figure 12. Variation of transverse deflection along the length of the cantilever beam for three different light focus positions on the beam at $200 \mathrm{~mW} / \mathrm{cm}^{2}$.

beam compared to the other two positions. In addition, the light focused at the fixed end position allowed the beam to bend more near the fixed end, which ultimately resulted in these having the same beam deflection. 


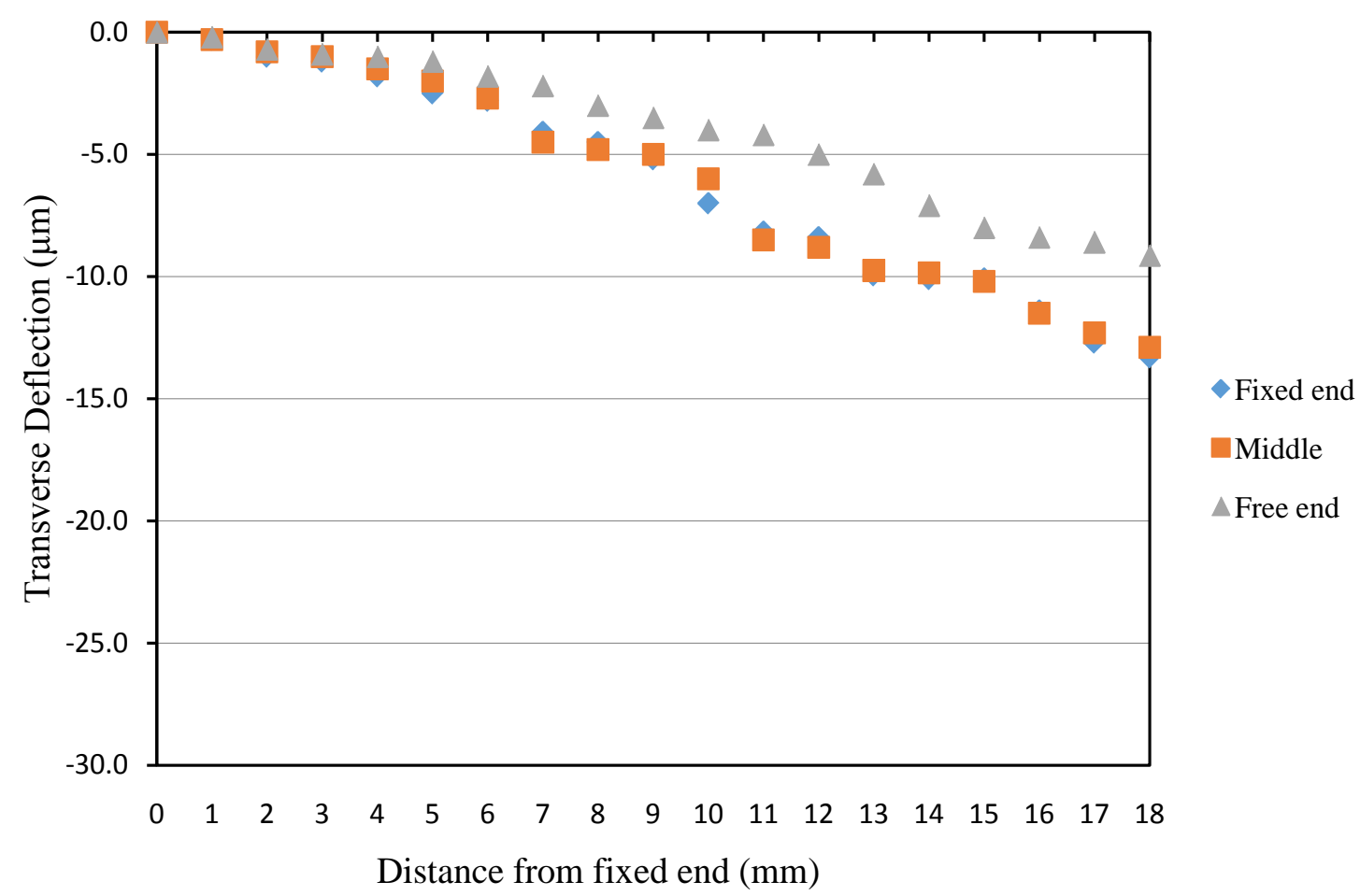

Figure 13. Variation of transverse deflection along the length of the cantilever beam for three different light focus positions on the beam at $100 \mathrm{~mW} / \mathrm{cm}^{2}$.

\subsubsection{Time Response of the Cantilever Beam Deflection at the Free End for Three Different Focused Positions}

High intensity UV light was focused at different locations on the cantilever beam.

Deflection at the free end of the cantilever beam was observed to measure the time needed to reach the steady state condition as shown in Figures 14-16 respectively. Time response of the cantilever beam neither had any major influence on the light intensity nor on the focused locations of the actuator beam. Rising time was about $20 \mathrm{sec}$ to reach $63 \%$ of the steady state maximum deflection. The cantilever beam was approaching the steady state after about $180 \mathrm{sec}$.

\subsubsection{Hysteresis of the PLZT Cantilever Beam}

The light was focused at the middle of the cantilever beam, and light was turned on and off for three times to observe the hysteresis in the actuator beam at a 200 $\mathrm{mW} / \mathrm{cm}^{2}$ light intensity. When the light turn on and off repeatedly, very small deflection on the cantilever beam was still observed when the light was still turned off as shown in Figure 17.

\subsection{Results for the Pulses of Light}

Tests were performed by placing an optical chopper in between the PLZT cantilever beam and the UV light source. The PLZT cantilever beam was exposed to illumination of pulses of light intermittently by the optical chopper. The two-slot blade optical chopper was run with a frequency of $0.5 \mathrm{~Hz}$, which made the beam to be exposed to illuminations of light for $1 \mathrm{sec}$ on and $1 \mathrm{sec}$ off. The experiment 


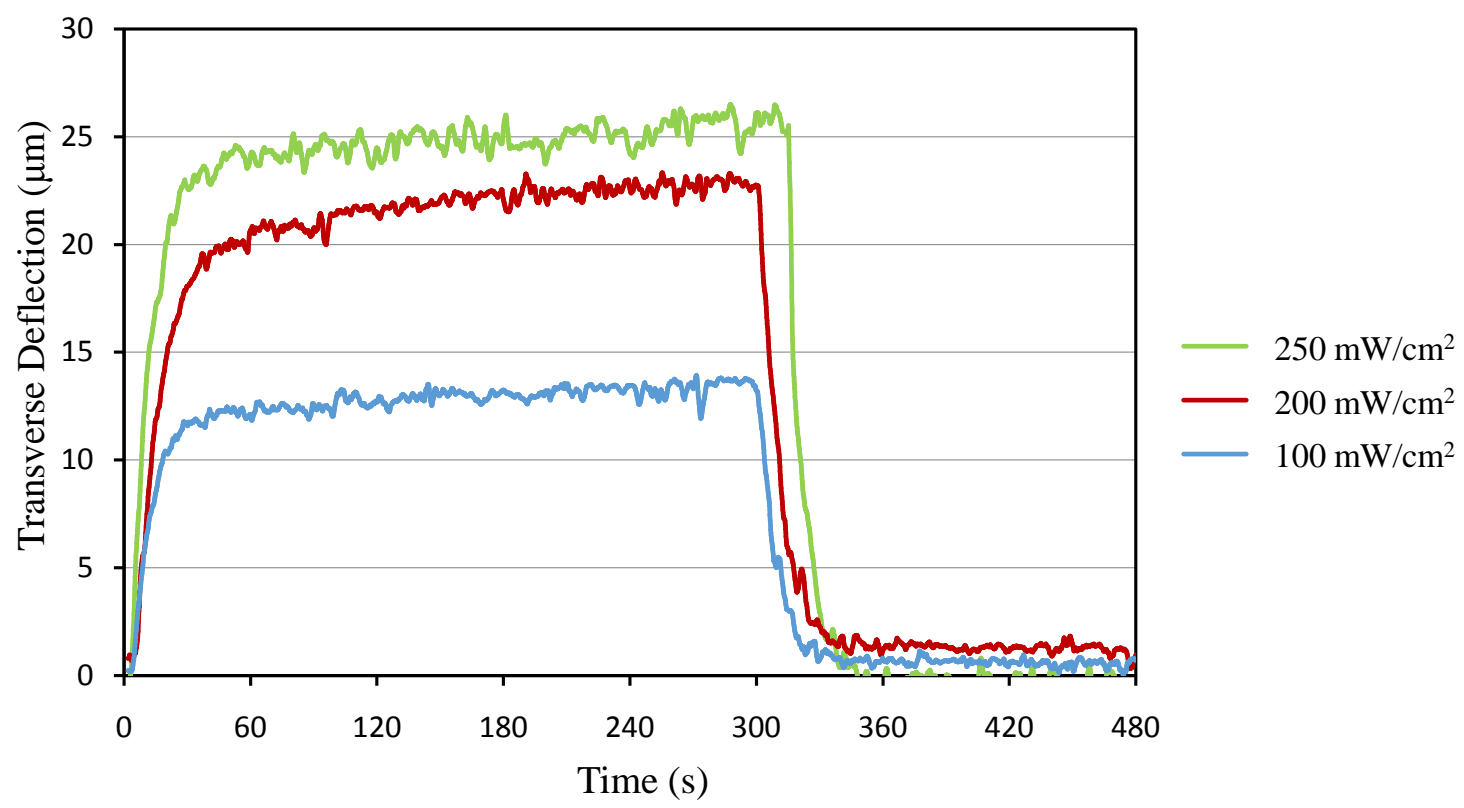

Figure 14. Comparison of time response on transverse deflection for three different light intensities when light was focused at the fixed end.

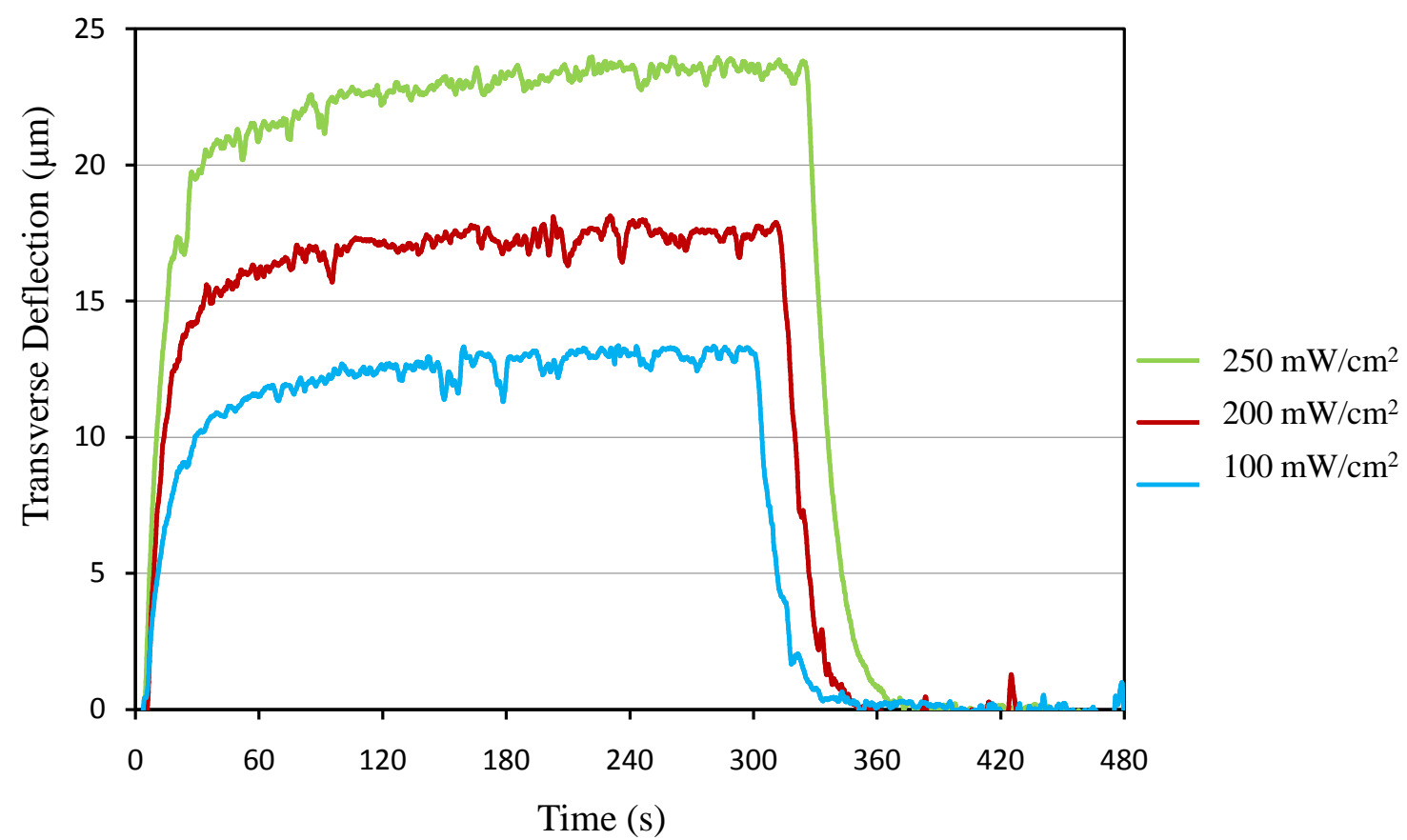

Figure 15. Comparison of time response on transverse deflection for three different light intensities when light was focused at the middle.

was conducted at light intensities of $250 \mathrm{~mW} / \mathrm{cm}^{2}, 200 \mathrm{~mW} / \mathrm{cm}^{2}$, and $100 \mathrm{~mW} / \mathrm{cm}^{2}$. In these pulses of light case, light was focused only at the middle of the cantilever beam.

3.2.1. Comparison of Transverse Deflection with the Light Intensity It has been observed that the magnitude of the corresponding transverse deflection 


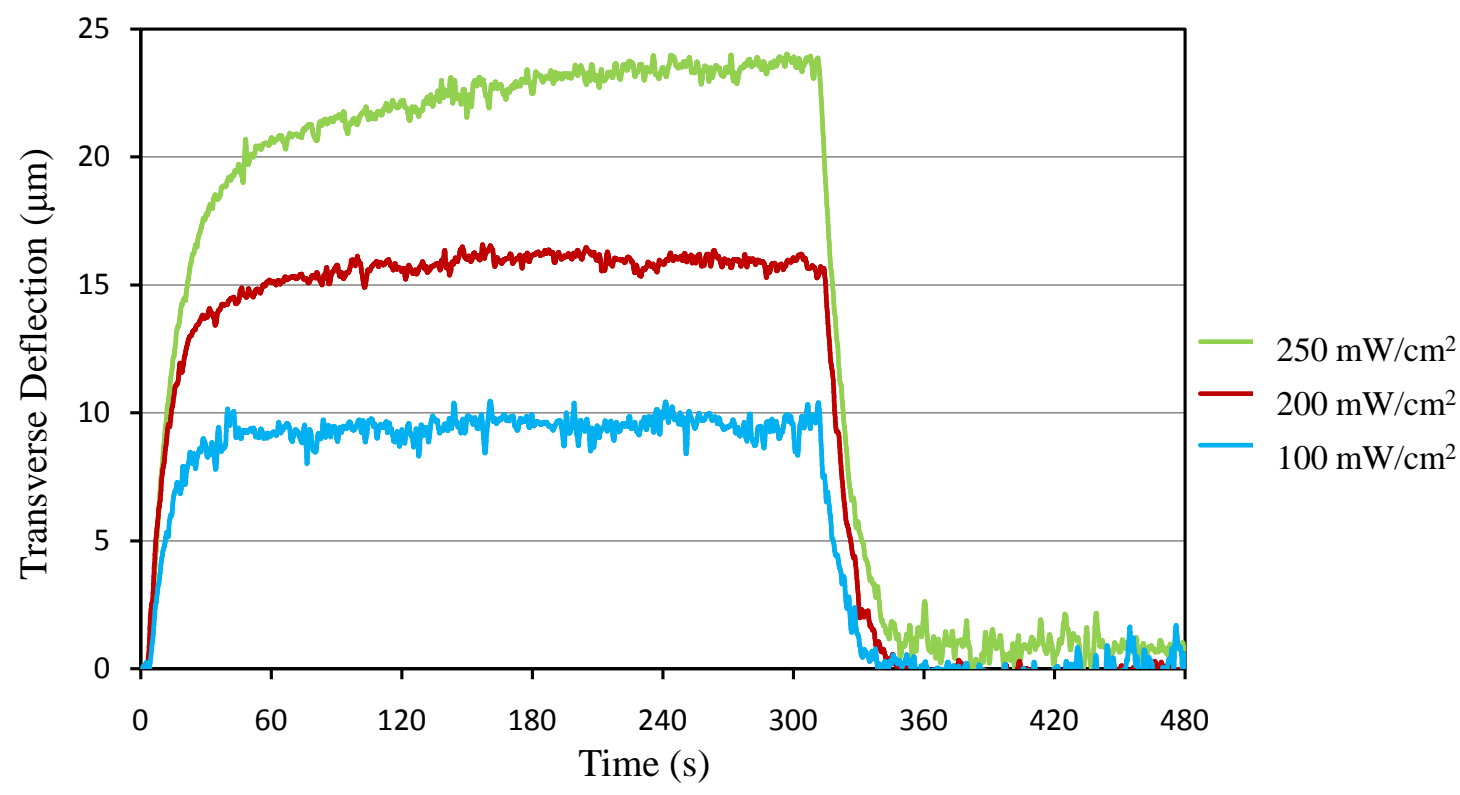

Figure 16. Comparison of time response on transverse deflection for three different light intensities when light was focused at the free end.

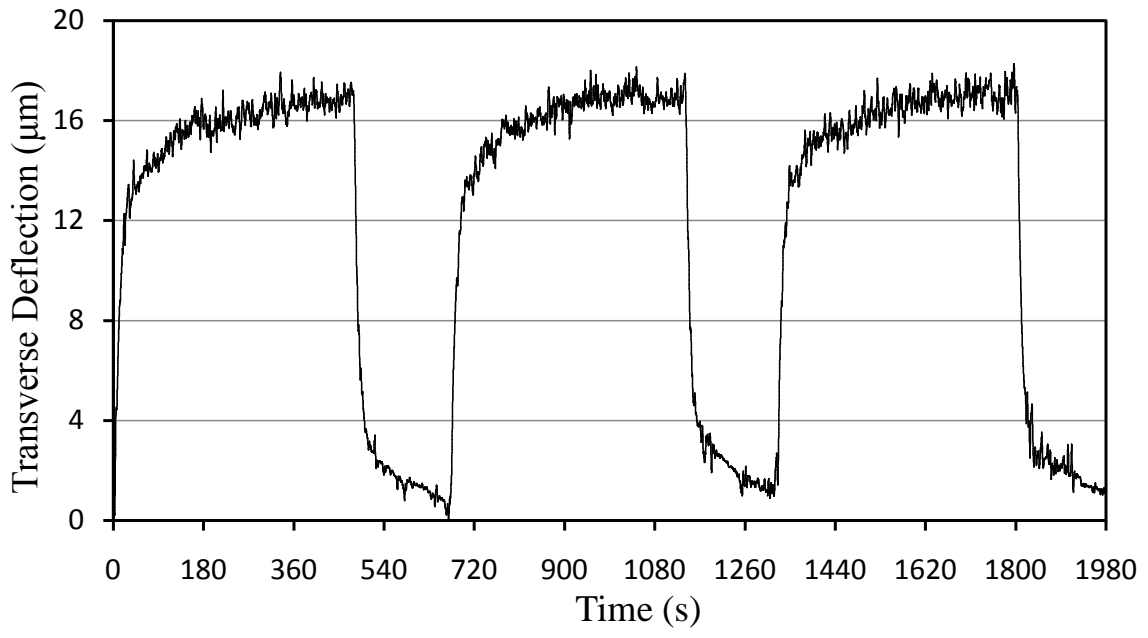

Figure 17. Hysteresis of the cantilever beam deflection at the free end.

along the length of the cantilever beam decreases in the pulses of light condition in comparison to the continuous light condition. Transverse deflection increases along the length of the actuator beam with the increase of distance from the fixed end as shown in Figure 18. It is also been observed that the deflection of the cantilever beam increases with increase of the light intensity as shown in Figure 19.

\subsubsection{Time Response of the Cantilever Beam Deflection at the Free End for the Pulses of Light}

The pulses of high intensity UV light were focused at the middle of the cantilever beam; deflection at the free end of the actuator beam was observed to measure the time needed to reach steady as shown in Figure 20. Time response of the 


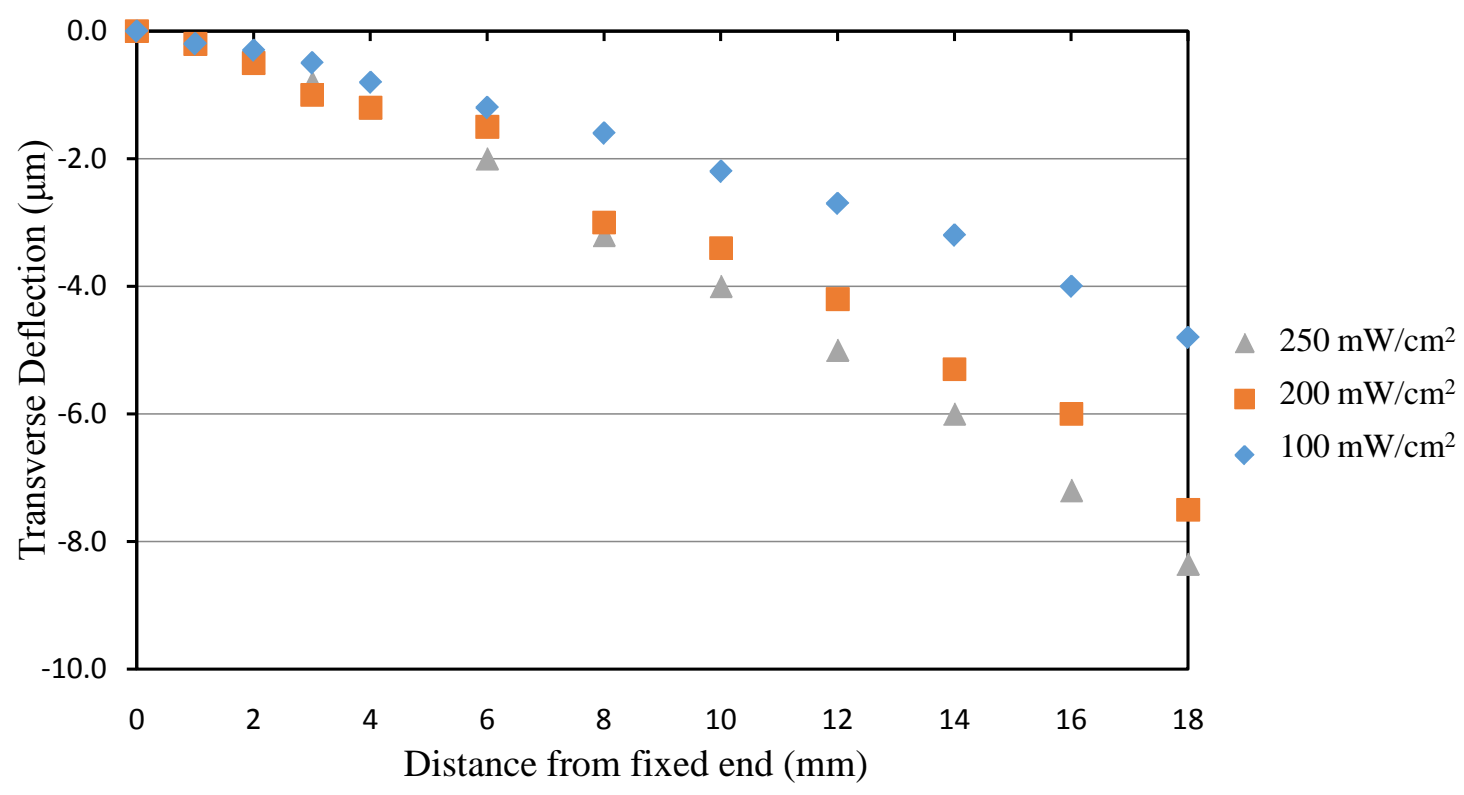

Figure 18. Transverse deflection along the length of the cantilever beam at three different light intensities for pulses of light condition.

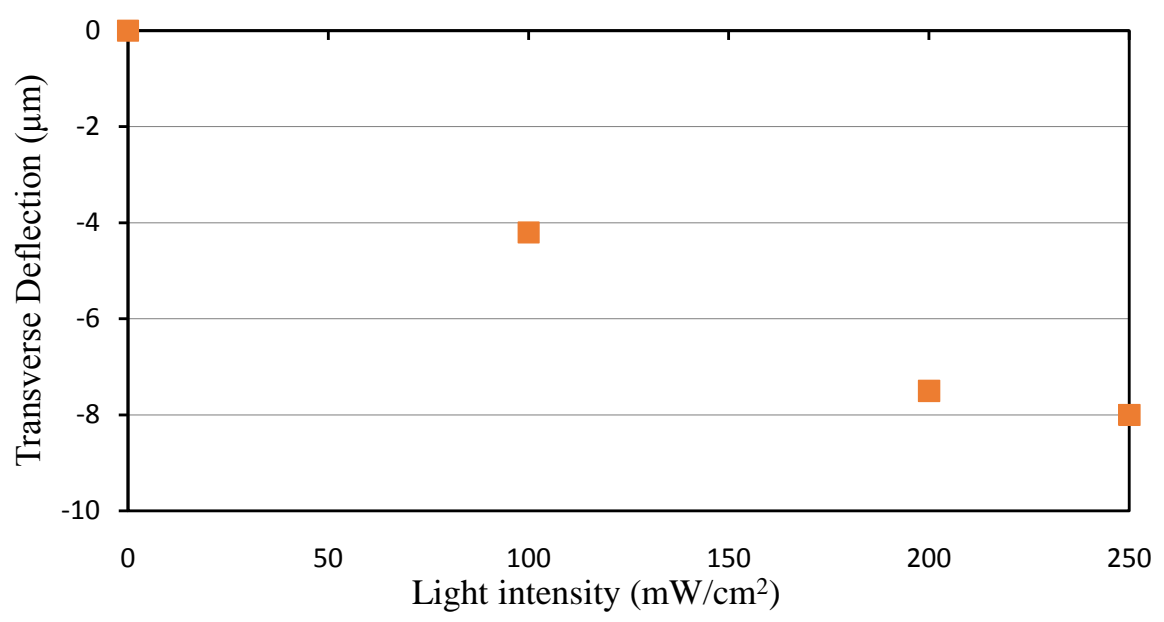

Figure 19. Transverse deflection depends on the light intensity in pulses of light condition.

cantilever beam has no major influence on the light intensities for the pulses of light condition. Rising time was about $20 \mathrm{sec}$ to reach $63 \%$ of the steady state maximum deflection. The deflection of the cantilever beam was approaching a steady state after about $180 \mathrm{sec}$.

\subsection{Comparison of Deflection Results for the Continuous and Pulses of Lights}

The transverse deflection along the length of the PLZT cantilever beam in a continuous light condition was compared to that of the pulses of light condition. Comparison was made between the continuous light and pulses of light conditions at three different light intensities when light was focused at the middle of 
the cantilever beam as shown in Figures 21-23. It has been noticed that, at each light intensity, the magnitude of the free end deflection of the beam for pulses of light was approximately $1 / 3^{\text {rd }}$ of the free end deflection of continuous light. In the pulses of light condition, the cantilever beam exposed to pulses of high intensity light, could not reach the maximum photostrictive effect in that amount

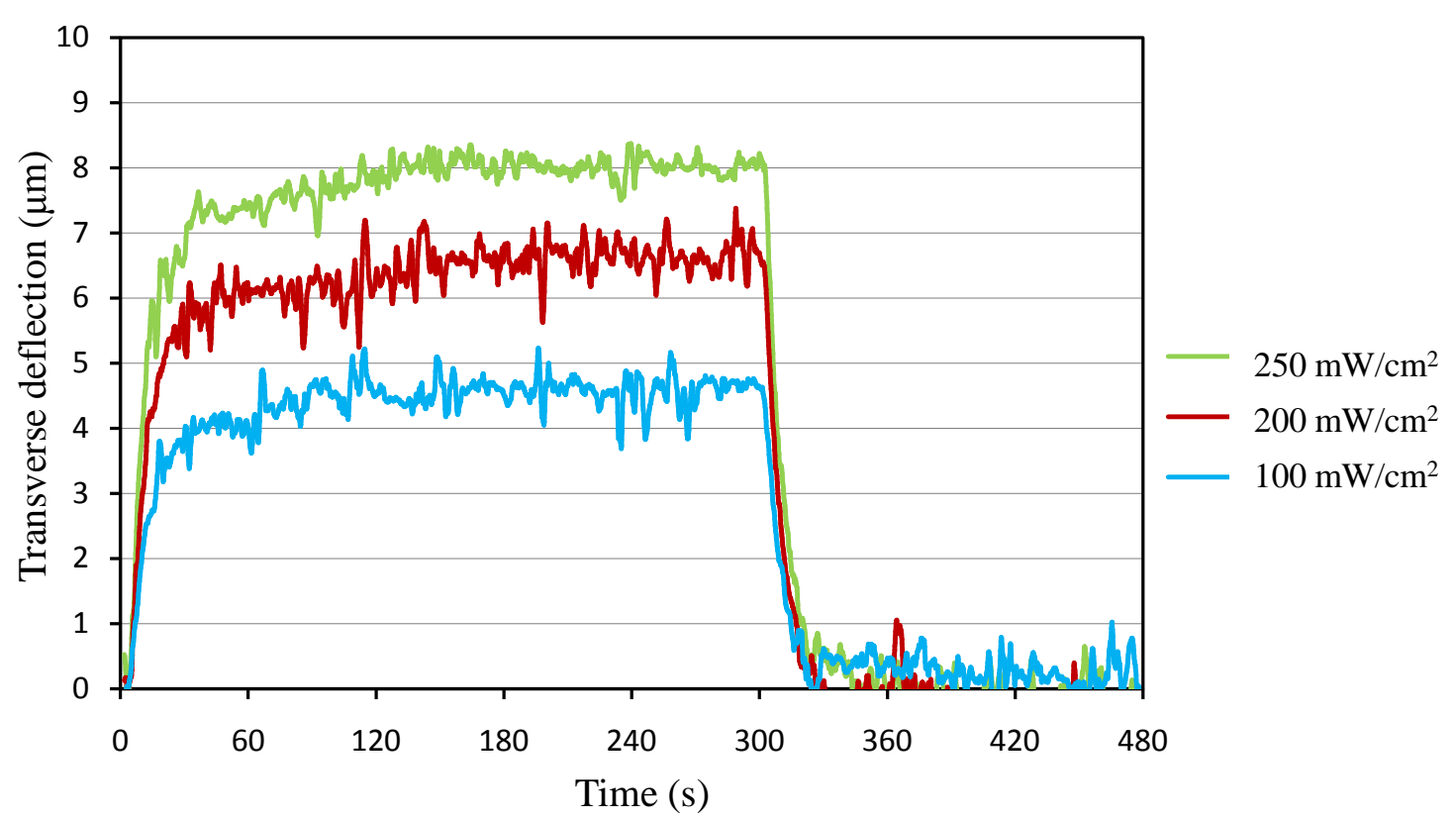

Figure 20. Comparison of time response on transverse deflection for three different light intensities in the pulses of light condition.

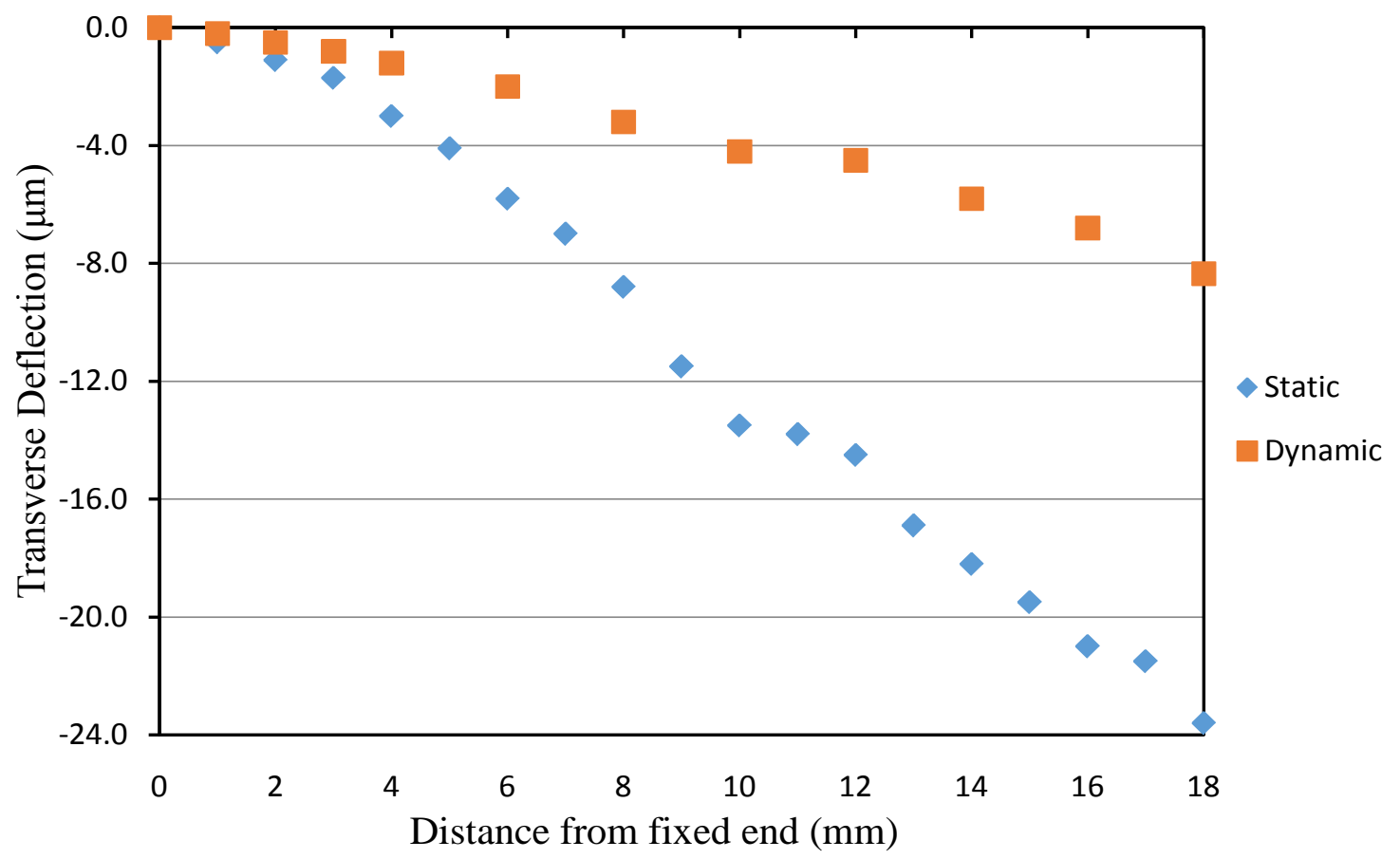

Figure 21. Comparison of transverse deflection between continuous and pulses of light conditions at $250 \mathrm{~mW} / \mathrm{cm}^{2}$ intensity. 


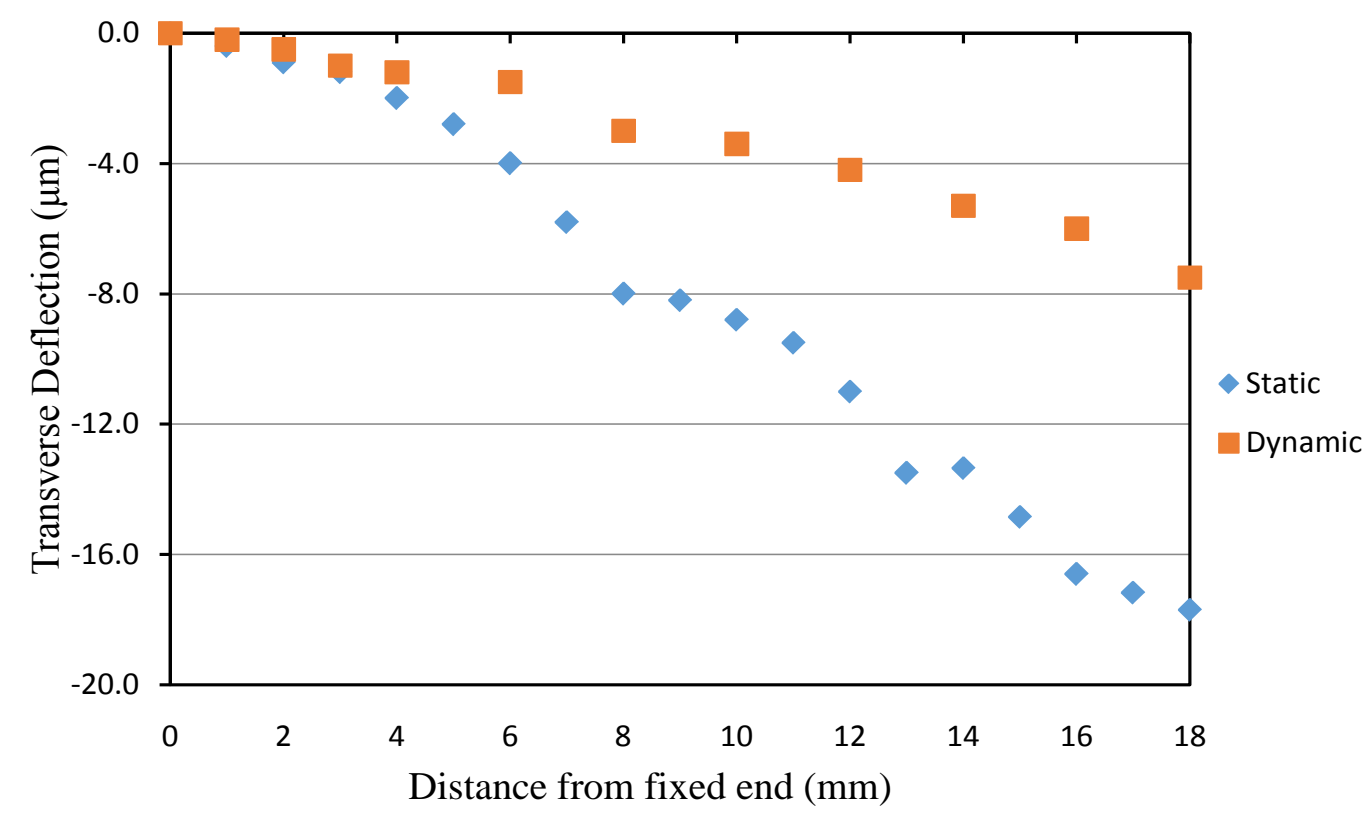

Figure 22. Comparison of transverse deflection between continuous and pulses of light conditions at 200 $\mathrm{mW} / \mathrm{cm}^{2}$ intensity.

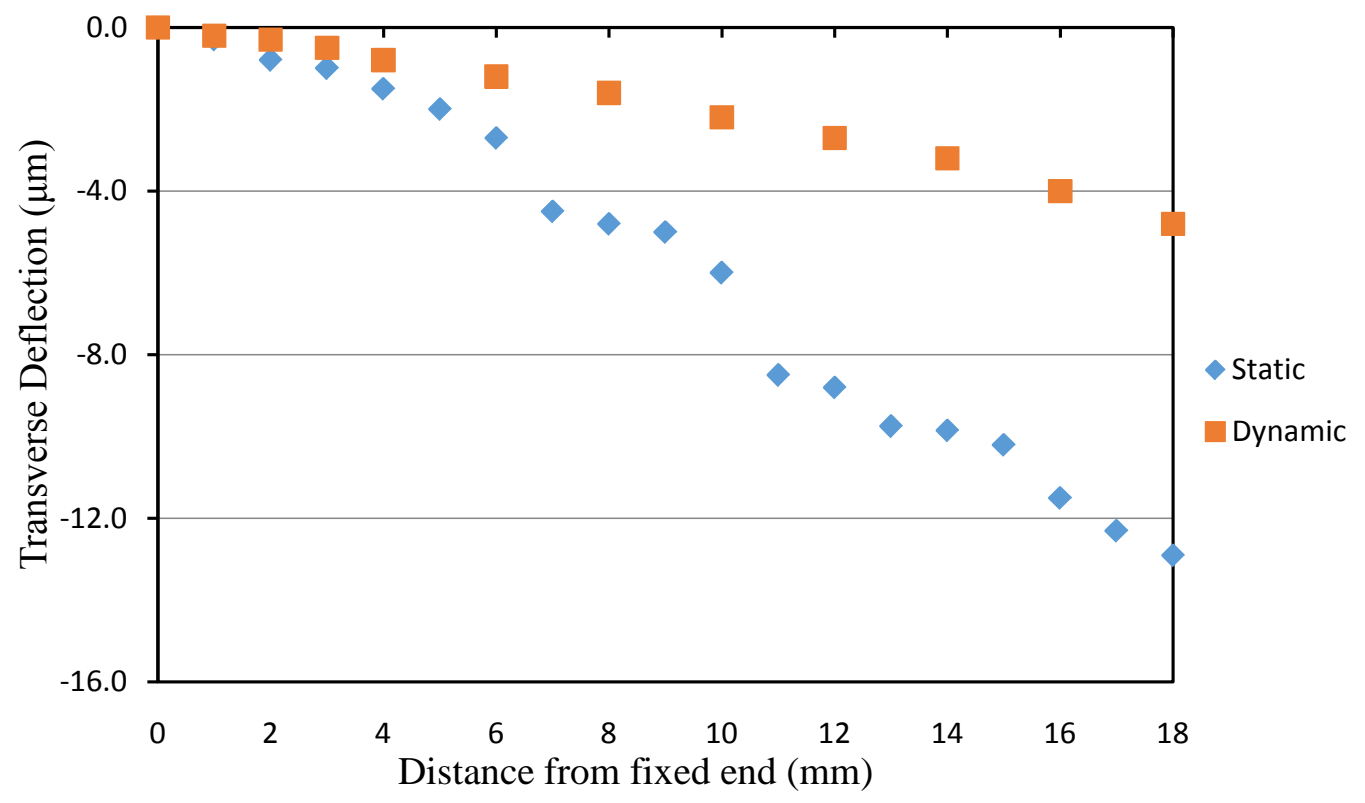

Figure 23. Comparison of transverse deflection between continuous and pulses of light conditions at 100 $\mathrm{mW} / \mathrm{cm}^{2}$ intensity.

of time that the continuous light condition could reach. That is why actuator beam deflection was less in the pulses of light condition than in continuous light condition.

\section{Conclusions}

From this experimental investigation, it has been observed that the continuous lights and the pulses of lights have a significant influence on the transverse deflec- 
tion of PLZT optical actuator; less deflection was observed for the pulses of light compare to the continuous light. The PLZT optical actuator could be used in MEMS applications via a wireless control but the time response of the actuator observed was slow.

From the current study, analysis, and results of this research, the following conclusions can be made:

1) Experimental transverse deflection of a cantilever beam increases with the increase of light intensity for both continuous lights and pulses of lights.

2) Maximum tip deflection at the free end of the cantilever beam for pulses of light was about $1 / 3^{\text {rd }}$ deflection of that for continuous light.

3) The light intensity and focused locations of the cantilever beam have no major influence on the time response. Rising time was observed to be about $20 \mathrm{sec}$ to reach $63 \%$ of the steady state the maximum deflection for both continuous lights and pulses of light conditions. Deflection of the cantilever beam was approaching a steady state after about $180 \mathrm{sec}$ for both continuous lights and pulses of lights.

\section{References}

[1] Fridkin, V.M. (1979) Photo Ferroelectrics. Springer Series in Solid State Sciences, Vol. 9, 85-113. https://doi.org/10.1007/978-3-642-81351-1_6

[2] Rahman, M. (2005) A Finite Element Approach to Model and Analyze Photostrictive Optical Actuators. PhD Dissertation, University of Alabama, Tuscaloosa.

[3] Kawaguchi, K., ichiki, M., Morikawa, Y. and Nakada, T. (2002) Electrical Properties of Photovoltaic PLZT and Its Application to Optical Motor. Ferroelectric, 273, 41-46.

[4] Tanimura, M. and Uchino, K. (1988) Effect of Impurity Doping on Photostriction in Ferroelectric Ceramics. Sensors and Materials, 1, 47-56.

[5] Sada, T., Inoue, M. and Uchino, K. (1987) Photostriction in PLZT Ceramics. Journal of the Ceramic Society of Japan, International Edition, 95, 499-504.

[6] Okuym, M. (1998) Micro Sensors and Micro Actuators using Ferroelectric Thin Films. Proceedings of the International Symposium on Micromechatronics and Human Science, Nagoya, 29-34.

[7] Satol, K., Sugama, A., Akahoshi, T., Kondo, M., Aoki, S. and Kurihara, K. (2007) Electro-Optic Effect of Lanthanum-Modified Lead Zirconate Titanate and Application to Optical Device. 16th IEEE International Symposium on Applications of Ferroelectrics, $827-828$.

[8] Huff, M.A. (2012) What Is Mems Technology? MEMS and Nanotechnology Exchange. https://www.mems-exchange.org/MEMS/what-is.html

[9] Chynoweth, A.G. (1956) Surface Space-Charge Layers in Barium Titanate. Physics Review, 102, 705-714. https://doi.org/10.1103/PhysRev.102.705

[10] Brody, P.S. (1975) High Voltage Photovoltaic Effect in Barium Titanate and Lead Titanate-Lead Zirconate Ceramics. Solid State Chemistry, 12, 193-200.

[11] Brody, P.S. (1983) Optomechnical Bimorph Actuator. Ferroelectrics, 50, 27-33. https://doi.org/10.1080/00150198308014428

[12] Qin, M., Kui, Y. and Yung, C.L. (2007) Photo Induced Current in $\left(\mathrm{Pb}_{0.97} \mathrm{La}_{0.03}\right)$ $\left(\mathrm{Zr}_{0.52} \mathrm{Ti}_{0.48}\right) \mathrm{O}_{3}$ Thin Films of Different Thicknesses. Integrated Ferroelectrics, 88, 58-67. https://doi.org/10.1080/10584580601098647

[13] Poosanaas, P., Dogan, A., Thakoor, S. and Uchino, K. (1998) Influence of Sample 
Thickness on the Performance of Photostrictive Ceramics. Journal of Applied Physics, 84, 1508-1512. https://doi.org/10.1063/1.368216

[14] Yao, K., Gan, B.K., Chen, M. and Shannigrahi, S. (2005) Large Photo-Induced Voltage in a Ferroelectric Thin Film with In-Plane Polarization. Applied Physics Letters, 87, Article ID: 212906.

[15] Tonokai, A., Takefumi, K., Daisuke, Y. and Koichi, S. (2010) PLZT Film Actuators Deposited by a Hydrothermal Method. IEEE International Conference on Robotics and Biomimetics, 1584-1589. https://doi.org/10.1109/ROBIO.2010.5723566

[16] Liang, L., Shaoping, W. and Feng, C. (2006) Characteristics of Photo-Mechanical Device Using PLZT Wafer. Proceedings of the 2 nd IEEE/ASME International Conference on Mechatronic and Embedded Systems and Applications, 1-4. https://doi.org/10.1109/MESA.2006.296973

[17] Thakoor, S., John, M.M. and James, A.C. (1996) The Role of Piezoceramic Microactuation for Advanced Mobility. IEEE International Symposium on Application of Ferroelectrics, 1, 205-211.

[18] Fukuda, T., Hattori, S., Arai, F., Matsuura, H., Hiramatsu, T., Ikeda, Y. and Maekawa, A. (1993) Characteristics of Optical Actuator-Servomechanisms using Bimorph Optical Piezoelectric Actuator. Proceedings of 1993 IEEE Robotics and Automation Conference, 618-623.

[19] Ichiki, M., Furue, H., Kobayashi, T., Morikawa, Y., Nonaka, K., Maeda, R., Nakada, T. and Endo, C. (2005) Ultraviolet Sensor of Non-Bias Type; Layered Film Structure of Photovoltaic Ferroelectrics. The 13th International Conference on Solid-State Sensors, Actuators and Microsystems, 2, 2107-2110.

[20] Mendinueta, J.M.D., Shinada, S., Furukawa, H. and Wada, N. (2017) Ultra-High-Capacity Optical Packet Switching Networks with Coherent Polarization Division Multiplexing QPSK/16QAM Modulation Formats. Photonics, 4, 27.

[21] Nashimoto, K., Tanaka, N., LaBuda, M., Ritums, D., Dawley, J., Raj, M. and Kudzuma, D. (2005) High-Speed PLZT Optical Switches for Burst and Packet Switching. IEEE 2nd International Conference on Broadband Networks, 2, 1118-1123.

[22] Nashimoto, K., Kudzuma, D. and Han, H. (2010) High-Speed Switching and Filtering using PLZT Waveguide Devices. 15th Opto Electronics and Communications Conference, 540-542.

[23] Furukawa, H., Naoya, W., Hiroaki, H., Naganori, T., Keiichi, N. and Tetsuya, M. (2008) 640 Gbit/S/Port Optical Packet Switch Prototype with Optical Buffer using $1 \times 8$ PLZT Optical Switch and Parallel Pipeline Buffer Manager. 34th European Conference and Exhibition on Optical Communication, 1-2.

[24] Uchino, K. (1989) Micro Walking Machine using Piezoelectric Actuators. Robotics and Mechatronics, 124, 44-47.

[25] Martin, S.J., Butler, M.A. and Lan, C.E. (1988) Ferroelectric Optical Image Comparator using PLZT Thin Films. Electronics Letter, 24, 1486-1487. https://doi.org/10.1049/el:19881014

[26] Thakoor, S., Poosanaas, P., Morookian, J.M., Yavrouian, A., Lowry, L., Marzwell, N.I., Nelson, J.G., Neurgaonkar, R.R. and Uchino, K. (1998) Optical Microactuation in Piezoceramics. Smart Structures and Materials Smart Electronics and MEMS. 5t $h$ Annual International Symposium on Smart Structures and Materials, San Diego, 20 July 1998.

[27] Shih, H.R. and Tzou, H.S. (2000) Opto-Piezothermoelastic Constitutive Modeling of a New 2-D Photostrictive Composite Plate Actuator. ASME Control of Vibration and Noise: New Millennium, 61. 
Submit or recommend next manuscript to OALib Journal and we will provide best service for you:

- Publication frequency: Monthly

- 9 subject areas of science, technology and medicine

- Fair and rigorous peer-review system

- Fast publication process

- Article promotion in various social networking sites (LinkedIn, Facebook, Twitter, etc.)

- Maximum dissemination of your research work

Submit Your Paper Online: Click Here to Submit

Or Contact service@oalib.com 